\title{
Vapour transport deposition of methylammonium iodide for perovskite solar cells
}

\author{
Florent Sahli, ${ }^{a^{*}}$ Nathanaël Miaz, ${ }^{a, b}$ Niccolò Salsi, ${ }^{a}$ Cédric Bucher, ${ }^{a}$ Aymeric Schafflützel, ${ }^{a}$ \\ Quentin Guesnay, ${ }^{a}$ Léo Duchêne, ${ }^{c}$ Bjoern Niesen, ${ }^{a, b,+}$ Christophe Ballif, ${ }^{a, b}$ Quentin Jeangros. ${ }^{a^{*}}$
}

${ }^{a}$ Ecole Polytechnique Fédérale de Lausanne (EPFL), Institute of Microengineering (IMT), Photovoltaics and Thin-Film Electronics Laboratory, Rue de la Maladière 71b, 2002 Neuchâtel, Switzerland.

b CSEM, PV-Center, Jaquet-Droz 1, 2002 Neuchâtel, Switzerland

c Empa, Swiss Federal Laboratories for Materials Science and Technology, Laboratory Materials for Energy Conversion, 8600 Dübendorf, Switzerland.

\#ow at Empa, Swiss Federal Laboratories for Materials Science and Technology 8600 Dübendorf, Switzerland

* Corresponding authors

KEYWORDS: organohalide deposition, chemical vapour deposition, organic vapour phase deposition, organic-inorganic perovskite, large-scale vapour deposition.

\section{ABSTRACT}

Vapour-based processes are promising options to deposit metal halide perovskite solar cells in an industrial environment due to their ability to deposit uniform layers over large areas in a controlled environment without resorting to the use of (possibly toxic) solvents. In addition, they yield conformal layers on rough substrates, an important aspect in view of producing perovskite/crystalline silicon tandem solar cells featuring a textured silicon wafer for light management. While the inorganic precursors of the perovskite are well suited for thermal evaporation in high vacuum, the sublimation of the organic ones is more complex to control due to their high vapour pressure. To tackle this issue, we developed a vapour transport deposition chamber for organohalide deposition that physically dissociates the organic vapour evaporation zone from the deposition chamber. Once evaporated, organic vapours, here methylammonium iodide (MAI), are transported to the deposition chamber by a carrier gas through a showerhead, ensuring a spatially homogeneous conversion of $\mathrm{PbI}_{2}$ templates to the perovskite phase, as demonstrated on substrate sizes of up to one 6-inch wafer. Furthermore, small-scale methylammonium lead iodide solar cells are also processed to validate the quality of the 
absorbers produced by this hybrid thermal evaporation/vapour transport deposition process.

\section{INTRODUCTION}

Perovskite solar cells (PSCs) are regarded as one of the most promising emerging photovoltaics (PV) technology due to their high efficiency and potential for fabrication at low costs. ${ }^{1,2}$ Single-junction cells with initial efficiencies over $25 \%$ have been recently certified, ${ }^{3}$ approaching the performance of the best crystalline silicon (c-Si) cells, the current PV industry standard. However, all of the high-efficiency PSCs reported so far still feature a small active area $\left(1 \mathrm{~cm}^{2}\right.$ or less) as they are usually processed using spin coating, a method difficult to upscale and industrialise at low costs. ${ }^{4}$ In addition, perovskite wet-chemistry processes usually involve toxic solvents such as dimethylformamide (DMF), an issue for large-scale manufacturing. Solution processing is also not optimal when depositing a perovskite top cell on top of a c-Si solar cell to form a tandem solar cell, a type of device that could potentially achieve efficiencies $>30 \%$. The issue is that monocrystalline Si cells used in the industry today feature an antireflective pyramidal texture of a few microns in height on their front side, a texture that cannot be covered in a conformal way with solution-based processes. ${ }^{5}$ Given these limitations, vapour-based deposition techniques offer several advantages as these should enable to conformally coat rough substrates with high uniformity across large areas. ${ }^{6-8}$ In addition, these methods have already been adopted by the PV industry..$^{9,10}$

Various vapour-based deposition techniques have been used to fabricate perovskite cells of different compositions. ${ }^{11,12}$ One step- and two-step physical vapour deposition (PVD) processes, where the inorganic and organic precursors are sublimed in high vacuum (usually $\sim 10^{-6}$ mbar) either simultaneously or sequentially, have been used to make perovskite single-junction devices achieving efficiencies of up to $20 \% .^{13,14}$ However, due to the high vapour pressure of organohalides and their tendency to deposit everywhere within the chamber, controlling the evaporation rate of each precursor individually by a quartz crystal microbalance has been challenging. ${ }^{15-17}$ Alternatively, controlling the organohalide deposition rate through the chamber pressure has been shown to yield valuable results. ${ }^{8,16}$ Nevertheless, the chamber pressure also depends on several parameters, such as the presence of water molecules or the outgassing of organohalides from chamber walls due to their low sticking coefficient. ${ }^{17,18}$ Organohalides have also been deposited by chemical vapour deposition (CVD). ${ }^{19-23}$ The thermally evaporated inorganic lead iodide precursor is converted to the perovskite phase at high temperatures $\left(\sim 150{ }^{\circ} \mathrm{C}\right)$ through an exposure to organohalide vapours in a multi-zone tube furnace (in 
a low vacuum). ${ }^{20}$ The organic material is sublimed in the higher temperature zone of the tube furnace and its vapours transported by a carrier gas to the $\mathrm{PbI}_{2}$ templates. For example, formamidinium (FA) iodide-based mini-modules with an active area of $91 \mathrm{~cm}^{2}$ could be produced with this hybrid method. ${ }^{12,20,23-27}$

While two-step hybrid PVD/CVD methods produce large-scale perovskite cells with ever-improving efficiencies, the use of a tube furnace comes with several drawbacks. The main issue is that the temperatures at the source(s) and at the substrate(s) are not fully independent due to their proximity, even when using a multi-zone furnace. This issue becomes especially severe when co-depositing from several sources placed along the tube length (e.g. when depositing mixed FA/MA perovskites or directly $\mathrm{MAPbI}_{3}$ from $\mathrm{PbI}_{2}$ and $\mathrm{MAI}^{28}$ ). Attempts to solve these issues have involved the design of reactors where evaporation sources are separated and placed in different temperaturecontrolled tubes each fed by a carrier gas..$^{29-31}$ The different tubes are connected to a substrate chamber that features its own temperature control. The carrier gas is used to collect the lead halide and organohalide vapours and drive them to the substrates, enabling the one-step CVD of perovskite absorbers. One issue with these evolutions to simple tube furnaces is that the organic vapour concentration may vary along the tube length, leading to poor reproducibility and spatial inhomogeneities in the deposition rate. ${ }^{24}$ To mitigate these issues, a showerhead-based reactor inspired by organic vapour phase deposition (OVPD) setups was designed to deposit hybrid organic-inorganic absorber from MAI and metal halide precursors.32,33 OVPD systems featuring a showerhead have been shown to yield homogeneous depositions of organic materials over large areas. ${ }^{34-37}$ Furthermore, the deposition rate of each precursor may be advantageously adjusted through their carrier gas flow rate and the deposition localised to the cooled substrates, ensuring a high materials utilisation. Regarding perovskites deposition by OVPD, it is worth noting that evaporating and then avoiding the condensation of lead halides on system parts such as the showerhead requires temperatures on the order of $350-400{ }^{\circ} \mathrm{C}$, temperatures that may lead to a degradation of MAI vapours. ${ }^{18}$ Despite providing additional control over the deposition process, the power conversion efficiencies of cells processed with these various upgrades to tube furnaces have not exceeded $10 \%$ at the proof-of-concept stage. ${ }^{29,30,32}$ Controlling precisely the evaporation of the inorganic and organic materials and reaching suitable perovskite layer properties has remained a complex task.

For enhanced control over the deposition of each precursor, a hybrid two-step PVD/CVD method is chosen here. Lead halide is thermally evaporated in high vacuum, while organohalides are then deposited using a custom-built vapour transport deposition (VTD) system featuring a showerhead. Our deposition system also bears some 
resemblance with OVPD systems and enables the independent control of the temperatures of the source, gas line, reactor walls, and substrates. Advantageously over conventional thermal evaporation, the system enables independent optimisation of the evaporation and deposition conditions and a high material utilisation by maintaining a temperature gradient between the cooler substrates and warmer chamber walls. Depending on the substrate temperature, MAI can be deposited in the OVPD regime (no reaction with the substrate to coat) or in the CVD regime (e.g. when there is a direct reaction with the $\mathrm{PbI}_{2}$-coated templates to form a perovskite). The properties of perovskite layers produced by $\mathrm{CVD}$ are correlated to organohalide deposition conditions, before producing proof-of-concept small-scale solar cells. Furthermore, the hybrid PVD/CVD method developed here enables to deposit perovskite layers with homogenous thicknesses and morphologies over larger areas, e.g. a $225 \mathrm{~cm}^{2}$ glass/ITO substrate or a 6-inch c-Si wafer textured on its front side.

\section{EXPERIMENTAL SECTION}

Device Fabrication. Glass/ITO substrates (15 Ohm/sq, Kintec) were cleaned by an oxygen plasma treatment and followed by a UV-Ozone treatment for $15 \mathrm{~min}$. Then, $1 \mathrm{~nm}$ of $\mathrm{LiF}(>99 \%$, Sigma Aldrich) and $6 \mathrm{~nm}$ of $\mathrm{C}_{60}(>99.95 \%$, NanoC) were thermally evaporated to form the electron transport layer in a home-built evaporation system at a substrate temperature of $30{ }^{\circ} \mathrm{C}$ and a base pressure of $<1.5 \times 10^{-6}$ Torr. Then, $150 \mathrm{~nm}$ of $\mathrm{PbI}_{2}(>99.99 \%$, Alfa Aesar) was evaporated in a Lesker Mini SPECTROS evaporation system. For layers produced by the sequential physical vapour deposition (PVD)/spin coating (SP) method, the $\mathrm{PbI}_{2}$ layer was converted to the final perovskite phase by spin coating a solution of methylammonium iodide (0.346 M, Greatcell solar) in ethanol at $3000 \mathrm{rpm}$ for $30 \mathrm{~s}$ using dynamic solution dispensing in an inert atmosphere, followed by an annealing step $\left(120^{\circ} \mathrm{C}, 30 \mathrm{~min}\right.$ in a $\mathrm{N}_{2}$-filled glovebox $)$. For perovskite solar cells produced by the sequential PVD/CVD process, the $\mathrm{PbI}_{2}$ layers were taken out of the glovebox in air and placed on the VTD deposition table (at a temperature between 70 and $160{ }^{\circ} \mathrm{C}$ ). Approximately $1 \mathrm{~g}$ of fresh MAI (Greatcell solar) was placed in the graphite crucible. The whole system (evaporator and deposition chamber) was then pumped down to a base pressure of 0.15 mbar ( 5 min of pumping). The carrier gas was then introduced at a flow rate controlled by a MFC (typically $800 \mathrm{sccm}, \mathrm{N}_{2}$ ). The temperature of the crucible was increased to the desired temperature at a rate of $\sim 10{ }^{\circ} \mathrm{C} / \mathrm{min}$ (10 to $15 \mathrm{~min}$ to reach the temperature set point). The evaporation was performed in steady-state conditions for 60 to 240 min. Once the evaporation finished, the temperature control of the evaporator was switched off, the process valve closed and the substrates were removed from the deposition chamber. The 
system was then pumped down again and flushed with $2800 \mathrm{sccm}$ of $\mathrm{N}_{2}$ (1500 from the evaporator line, 800 from the gas mixing line) to prevent any condensation of organics in the evaporation and gas transport line until the crucible reached a temperature below $100{ }^{\circ} \mathrm{C}$. The perovskite films were transferred back to a glovebox filled with $\mathrm{N}_{2}$. The perovskite layers were washed by a dynamic spin coating of isopropanol (IPA 99\%, Sigma-Aldrich) at $3000 \mathrm{rpm}$ for $30 \mathrm{~s}$. It is noteworthy to mention that only the layers destinated for cells underwent this washing step. The samples were then annealed for $3 \mathrm{~min}$ at $100^{\circ} \mathrm{C}$ using a hotplate to remove any IPA traces. A solution of spiro-OMeTAD in chlorobenzene $\left(72.3 \mathrm{mg} \mathrm{mL}^{-1} 2,2^{\prime}, 7,7^{\prime}\right.$-tetrakis $(\mathrm{N}, \mathrm{N}-$ di-4-methoxyphenylamino)-9,9'-spirobifluorene, $>99.5 \%$, Lumtec), $28.8 \mu \mathrm{L} \mathrm{mL}{ }^{-1}$ 4-tertbutylpyridine, $>96.0 \%$, TCI, and $17.5 \mu \mathrm{L} \mathrm{mL}^{-1}$ stock solution of $520 \mathrm{mg} \mathrm{mL}^{-1}$ lithium bistrifluoromethylsulfonyl imide, $>97.0 \%$, Sigma-Aldrich, in acetonitrile) was then spin coated at $4000 \mathrm{rpm}$ for $30 \mathrm{~s}$. Finally, $100 \mathrm{~nm}$ of gold was evaporated at a rate of $1 \AA$ / $/ \mathrm{s}$ to form the rear electrode.

Characterisation methods. A UV-vis-NIR spectrophotometer (PerkinElmer Lambda 900) with an integrating sphere was used to acquire total reflectance, transmittance and absorbance spectra. Current density-voltage $(J-V)$ measurements were performed using a two lamp (halogen and xenon) class AAA WACOM sun simulator with an AM1.5G irradiance spectrum of $1000 \mathrm{~W} \mathrm{~m}^{-2}$. Shadow masks were used to define the illuminated area $\left(0.25 \mathrm{~cm}^{2}\right)$ and the cells were measured with a scan rate of $100 \mathrm{mV} \mathrm{s}^{-1}$. External quantum efficiency (EQE) spectra were obtained using a custom-made spectral response set-up with a lock-in amplifier using chopped light at a frequency of $232 \mathrm{~Hz}$. XRD measurements were carried out in air (RH of 30\%) using an Empyrean diffractometer (Panalytical) equipped with a PIXcel-1D detector. The diffraction patterns were measured using a $\mathrm{Cu} \mathrm{K} \alpha$ radiation (wavelength of $1.54 \AA$ ). The samples were neither washed by IPA nor annealed before XRD measurements. Secondary electron SEM images were acquired with an acceleration voltage of $3 \mathrm{kV}$ using either an Everhart-Thornley or an in-lens detector in a Zeiss Gemini 2 microscope. Atomic force microscopy (AFM) was performed using a Dimension Edge system (Bruker). AFM and SEM images were taken directly after fabrication to prevent moisture ingress and degradation. Infrared absorption spectra were obtained using a Fourier transform infrared (FTIR) spectrometer (Bruker Vertex 80v) equipped with a RT-DTGS detector and a KBr beamsplitter. The measurements were performed in ambient conditions. The layers analysed were deposited on $240 \mu \mathrm{m}$-thick doubleside-polished c-Si wafers. ${ }^{1} \mathrm{H}$ liquid nuclear magnetic resonance spectrometry (NMR) was done using an AVANCE ${ }^{\mathrm{TM}}$ III HD $400 \mathrm{MHz}$ Spectrometer (Bruker). The samples (organohalide 
powders or organohalide condensates on c-Si wafers) were dissolved in $600 \mu 1$ DMSO-6d (99.8\%, MagniSolv) and transferred to a NMR test tube. $1 \mu 1$ of hydroiodic acid was added to acidify the solution to prevent proton exchange. ${ }^{40}$ Thermogravimetric analysis-mass spectrometry (TGA-MS) experiments were conducted using a Netzsch STA449F3 Jupiter differential scanning calorimetry (DSC)/TGA setup coupled with a Netzsch QMS 403 mass spectrometer. The powder samples were briefly pre-ground inside an Ar-filled glovebox and loaded (10-20 mg) in aluminium crucibles sealed to prevent air and humidity exposure during the transfer to the TGA-MS apparatus. A small hole was made in the crucible lid just before the measurement to allow sublimed species to escape. After two flushing cycles with helium gas, the samples were heated from 30 to $400{ }^{\circ} \mathrm{C}$ at $5{ }^{\circ} \mathrm{C} \mathrm{min}-1$ and held at $400{ }^{\circ} \mathrm{C}$ for 30 min under a helium flow, which served as a carrier gas for the mass spectrometer.

\section{RESULTS AND DISCUSSION:}

Setup description. Figure 1 describes the vapour transport deposition (VTD) setup schematically. In brief, it consists in a reaction chamber and a remote evaporation unit connected by a gas transport line. The heated carrier gas $\left(\mathrm{N}_{2}\right)$ is fed into the evaporator to drive the evaporated organohalides into the deposition chamber. To prevent organohalide condensation in the evaporator and gas transport lines, the $\mathrm{N}_{2}$ carrier gas is heated, as are the gas line walls and deposition chamber (by heating blankets). A showerhead (heated to $170{ }^{\circ} \mathrm{C}$ ) is placed at the inlet of the chamber to ensure a uniform deposition over the deposition table (which can accommodate up to one 6-inch c-Si wafer). The temperature of the substrate can be varied from $70{ }^{\circ} \mathrm{C}$ to $180^{\circ} \mathrm{C}$. A primary pump is attached to the bottom of the chamber and the overall pressure is controlled by a butterfly valve. The evaporation of MAI is performed in a graphite crucible, whose temperature is directly monitored by a thermocouple. More details about the VTD setup can be found in the text of the supplementary information and in Figure S1. 


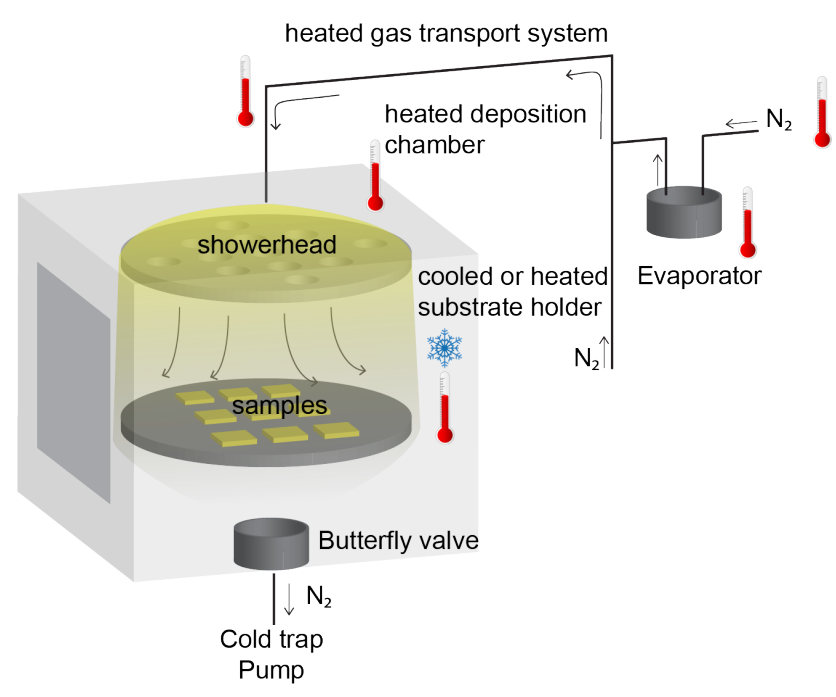

Figure 1: Simplified schematic of the VTD setup.

MAI transport to the deposition chamber. A high concentration of MAI molecules should reach the deposition chamber to efficiently drive the perovskite formation reaction. It implies that a sufficient amount of MAI has to be evaporated with few MAI molecules condensing during transport to the deposition chamber or degrading during evaporation or transport. To assess evaporation and transport conditions, the substrate holder was maintained at a sufficiently low temperature to condense MAI on c-Si or glass substrates (similar to OVPD growth regimes). Condensation on the chamber walls is avoided by maintaining their temperature $>150{ }^{\circ} \mathrm{C}$. Figure $2 \mathbf{a}$ shows a series of Fourier-transform infrared spectroscopy (FTIR) spectra of fresh MAI and evaporated MAI deposited on c-Si with the crucible temperature ( $\left.T_{\text {crucible }}\right)$ set to temperatures ranging from 180 to $220^{\circ} \mathrm{C}$ for 2 hours. Evaporation is minimal at $180^{\circ} \mathrm{C}$. MAI evaporated at $200{ }^{\circ} \mathrm{C}$ and above is chemically similar to the fresh compound based on the $\mathrm{N}-\mathrm{H}$ stretching vibration at 3000-3300 $\mathrm{cm}^{-1}$ and $\mathrm{C}-\mathrm{H}_{3}$ rocking at 915 and $1244 \mathrm{~cm}^{-1}$ (Figure $\mathbf{2 a}$, see Table $\mathrm{S} 1$ for the different FTIR vibration modes of $\left.\mathrm{MAI}^{4,38}\right)$. Higher evaporation temperatures lead to higher deposition rates, as highlighted by the increase in MAI vibration modes when the temperature is raised to $220^{\circ} \mathrm{C}$.

The chemical composition of the deposited layers was also investigated by liquid ${ }^{1} \mathrm{H}$ nuclear magnetic resonance spectroscopy ( ${ }^{1} \mathrm{H}$ NMR) (Figure 2b). The resonances from the amine $\mathrm{NH}_{3}(7.5 \mathrm{ppm})$ and methyl groups (2.3-2.4ppm) of materials evaporated at 200 ${ }^{\circ} \mathrm{C}$ and above are similar to those obtained with spin-coated MAI layers, confirming the presence of pure MAI. The integration of the proton signals yields a ratio of $\approx 1: 1$ between both functional groups, as expected for MAI. ${ }^{39,40}$ The ${ }^{1} \mathrm{H}$ NMR spectrum with $T_{\text {crucible }}$ set to $220^{\circ} \mathrm{C}$ indicates that some degradation starts to occur, as indicated by the presence of the three equidistant peaks starting at $\sim 7 \mathrm{ppm}$, corresponding to ${ }^{1} \mathrm{H}-{ }^{14} \mathrm{~N} J$ - 
coupling in $\mathrm{NH}_{4}{ }^{+}$cations. ${ }^{40}$ These $\mathrm{NH}_{4}{ }^{+}$cations, which could not be directly detected by FTIR or thermogravimetry-mass spectrometry (TGA-MS, Figure S2), result from the reversible protonation of $\mathrm{NH}_{3}$, which originates from the degradation of MAI into $\mathrm{NH}_{3}$ and $\mathrm{CH}_{3} \mathrm{I}^{41}$ Finally, it should be mentioned that the powder inside the crucible remains chemically pristine, even after $2 \mathrm{~h}$ at $220{ }^{\circ} \mathrm{C}$ (Figure S3a). Furthermore, no impurities are detected in the powder left in the crucible and in the condensate deposited on the deposition table after 5 evaporations $\left(>10 \mathrm{~h}\right.$ at a $T_{\text {crucible }}$ of $\left.200^{\circ} \mathrm{C}\right)$, confirming that the same MAI powder can be reused for several evaporations (Figure S3b).

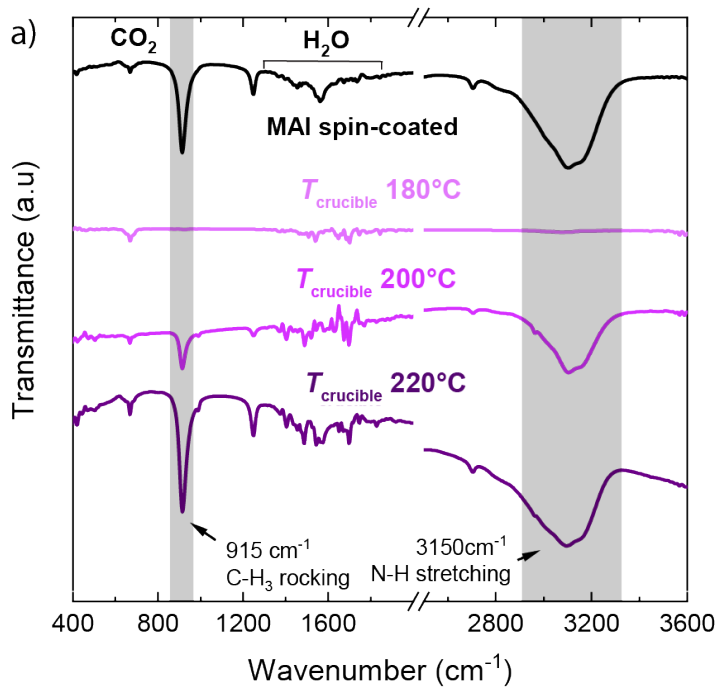

b)
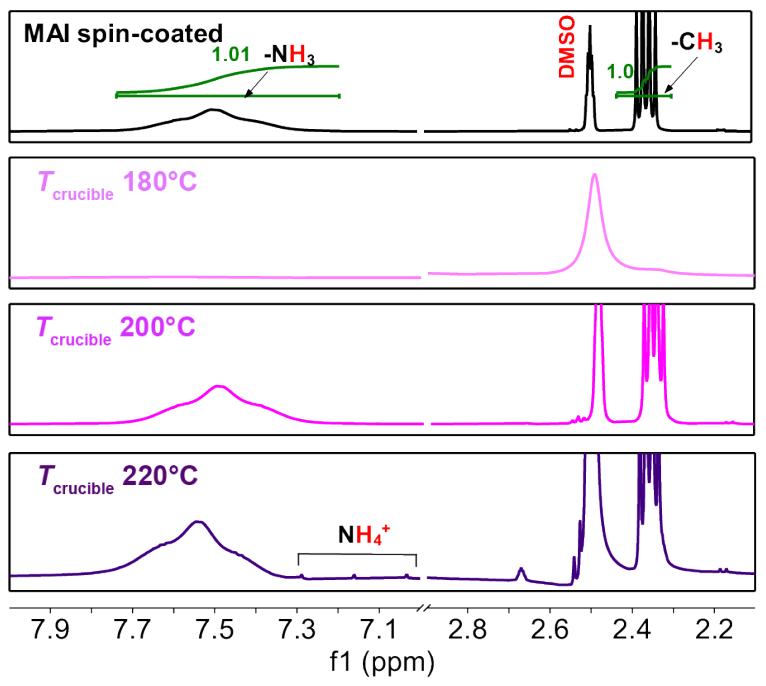

Figure 2: a) FTIR spectra of spin-coated (black) and evaporated (purple) MAI deposited on a c-Si wafer in the OVPD regime with the deposition table at $70{ }^{\circ} \mathrm{C}$ and $T_{\text {crucible }}$ set to $180{ }^{\circ} \mathrm{C}, 200$ ${ }^{\circ} \mathrm{C}$ and $220{ }^{\circ} \mathrm{C}, \mathrm{b}$ ) corresponding ${ }^{1} \mathrm{H}$ NMR spectra of as purchased (black) and MAI (purple) evaporated at various temperatures and condensed on the deposition table.

The gas line that connects the evaporator to the chamber must remain at high temperature to prevent any MAI condensation during transport towards the substrates. FTIR transmittance measurements indicate that MAI does not reach the chamber when setting the gas line temperature ( $T_{\text {gas line }}$ ) to $100{ }^{\circ} \mathrm{C}$ (Figure 3a). Increasing this temperature to $150{ }^{\circ} \mathrm{C}$ and $200{ }^{\circ} \mathrm{C}$ ensures MAI transport to the chamber, in larger quantity for the latter case. The $\mathrm{N}_{2}$ carrier gas is also heated upstream of the evaporator. At equivalent preheating temperature ( $\left.T_{\text {preheating }}\right)$ set point, the carrier gas temperature measured at the evaporator inlet scales linearly with flow rate (Figure S4), which is mainly due to the improved thermal conductance at higher pressures. For example, with a flow rate of 800 sccm and a $T_{\text {preheating }}$ set point of $150^{\circ} \mathrm{C}$, the carrier gas reaches a temperature of $60{ }^{\circ} \mathrm{C}$ at 
the evaporator inlet (Figure S4). Preheating the carrier gas to these temperatures favours MAI transport to the deposition chamber Figure $\mathbf{3 b}$.
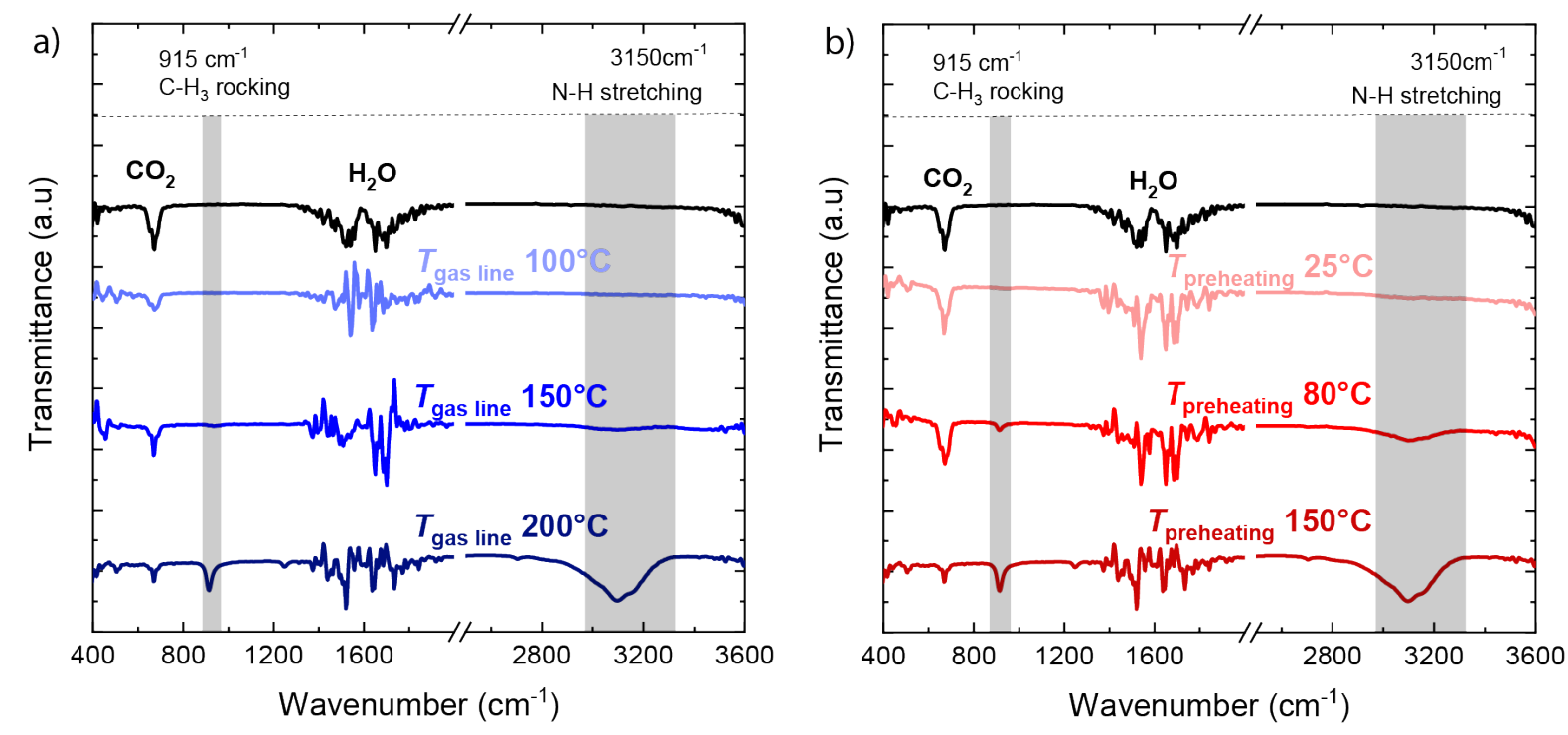

Figure 3: FTIR spectra of MAI deposited on the deposition table by OVPD $\left(T_{\text {substrate }}\right.$ of $70{ }^{\circ} \mathrm{C}$, $T_{\text {crucible }}$ of $200{ }^{\circ} \mathrm{C}$, gas flow of $800 \mathrm{sccm}$, working pressure of 4 mbar, deposition time of 2 hours) as a function of a) the gas line temperature ( $\left.T_{\text {gas line }}\right)$ and b) carrier gas preheating temperature ( $\left.T_{\text {preheating }}\right)$.

Perovskite formation by exposing $\mathrm{PbI}_{2}$ templates to MAI vapours. After identifying optimum MAI evaporation and transport conditions ( $T_{\text {preheating }}$ of $150{ }^{\circ} \mathrm{C}, T_{\text {crucible }}$ of 200 ${ }^{\circ} \mathrm{C}, T_{\text {gas lines }}$ of $200{ }^{\circ} \mathrm{C}$ ), we now use substrates coated with $150 \mathrm{~nm}$ of thermally evaporated $\mathrm{PbI}_{2}$ (evaporation rate of $1 \AA$ /s) to investigate the formation of the perovskite phase, especially as a function of the substrate temperature $\left(T_{\text {substrate }}\right){ }^{20,22}$ The adsorption/desorption of MAI and its reaction with $\mathrm{PbI}_{2}$ strongly depend on $T_{\text {substrate }},{ }^{18}$ as shown in Figure 4 for temperatures ranging from $80{ }^{\circ} \mathrm{C}$ to $160{ }^{\circ} \mathrm{C}$. Three different film growth regimes are observed depending on $T_{\text {substrate }}$ when exposing $\mathrm{PbI}_{2}$ to $\mathrm{MAI}$, as discussed below.

A first growth regime is observed with a $T_{\text {substrate }}<100{ }^{\circ} \mathrm{C}$. In these conditions, a significant amount of MAI accumulates on the substrates and deposition table after 2 hours of deposition (see white colouration in Figure 4a). This surface accumulation of MAI can also be tracked using the FTIR signal of MAI deposited on c-Si in the same conditions (Figure 4b). These data indicate that MAI condenses (on c-Si) at a $T_{\text {substrate }}$ of up to $100{ }^{\circ} \mathrm{C}$, while higher temperatures seem to prevent its adsorption. This accumulation of MAI seen in Figure $\mathbf{4 a - b}$ is not directly observed in the diffraction patterns of Figure 4c. Before accumulating on the substrate surface, MAI vapours fully 
convert the $\mathrm{PbI}_{2}$ templates to a perovskite alpha phase already after 1 hour of deposition at $80^{\circ} \mathrm{C}$. Exposing this perovskite phase to MAI vapours for 1 more hour (bringing the total deposition time to 2 hours) leads to its oversaturation with MAI and eventually to a phase change. A hydrated $\left(\mathrm{CH}_{3} \mathrm{NH}_{3}\right)_{4} \mathrm{PbI}_{6} \cdot 2 \mathrm{H}_{2} \mathrm{O}$ phase forms when the oversaturated perovskite is exposed to (humid) air at room temperature (see Figure 4c, the diffractograms are acquired in air). ${ }^{38}$ Annealing this hydrated phase at $100{ }^{\circ} \mathrm{C}$ for $10 \mathrm{~min}$ removes $\mathrm{H}_{2} \mathrm{O}$ from the film and reverses the crystal structure to a mixture between the photoactive perovskite phase and pure MAI (Figure S5). The hydrated phase then forms back when the layer is exposed to humid air again. The second regime occurs for a $T_{\text {substrate }}$ between $120{ }^{\circ} \mathrm{C}$ and $140{ }^{\circ} \mathrm{C}$. There, no MAI oversaturation occurs (Figure 4b) and a perovskite alpha phase is detected by XRD after 2 hours (Figure 4c). These results indicate that an equilibrium between MAI adsorption, desorption, and its reaction with $\mathrm{PbI}_{2}$ is reached at these temperatures. ${ }^{18}$ Finally, a third regime is observed at a temperature of $160{ }^{\circ} \mathrm{C}$. No reaction occurs between $\mathrm{PbI}_{2}$ and MAI after 120 min of deposition, likely due to the fact that this high temperature prevents any MAI adsorption on $\mathrm{PbI}_{2}$. 

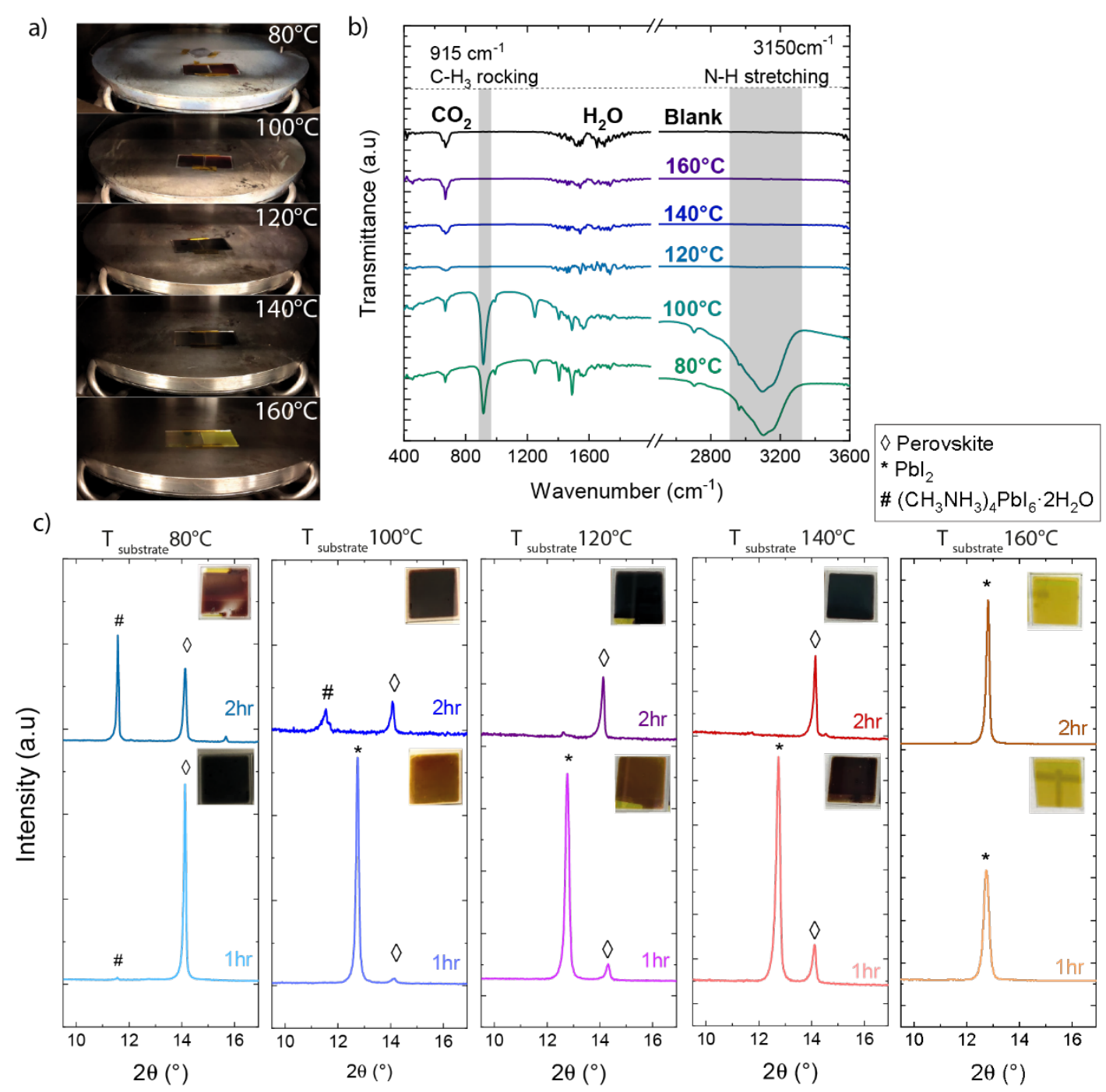

Figure 4: Effects of $T_{\text {substrate }}$ on the perovskite formation, with a) pictures of the deposition table featuring $\mathrm{PbI}_{2}$-coated glass substrates (2 hours of deposition), b) FTIR spectra of the corresponding MAI condensed on bare c-Si wafers (2 hours of deposition) and c) X-ray diffractograms and pictures of $\mathrm{PbI}_{2}$ templates exposed to MAI for $1 \mathrm{~h}$ and $2 \mathrm{~h}$ for various $T_{\text {substrate }}$. Deposition conditions are $T_{\text {crucible }}$ of $200{ }^{\circ} \mathrm{C}$, carrier gas flow of $800 \mathrm{sccm}$, working pressure of 3.7 mbar.

Figure 4c shows that the perovskite formation reaction occurs faster when $T_{\text {substrate }}$ is kept low, with a full perovskite conversion observed in less than 1 hour at $80{ }^{\circ} \mathrm{C}$. Still, these lowtemperature conditions lead oversaturation and eventually to a non-photoactive phase upon exposure to humid air as discussed above. Full conversion without oversaturation is observed after 2 hours at $140{ }^{\circ} \mathrm{C}$. Similarly, by maintaining $T_{\text {substrate }}$ constant and by varying $T_{\text {crucible }}$ from $180{ }^{\circ} \mathrm{C}$ to $220{ }^{\circ} \mathrm{C}$, the perovskite conversion rate can be controlled as well (Figure S6). In addition to its influence on the perovskite formation kinetics, $T_{\text {substrate }}$ also impacts the perovskite 
morphology (Figure S7). Higher temperatures lead to a larger perovskite grain size, with some grains reaching lateral dimensions exceeding $800 \mathrm{~nm}$ at $140{ }^{\circ} \mathrm{C}$. At a $T_{\text {substrate }}$ of $120{ }^{\circ} \mathrm{C}$, similar grain sizes and morphologies are obtained for layers processed by $\mathrm{PVD}\left(\mathrm{PbI}_{2}\right) /$ spin-coating (MAI) and PVD $\left(\mathrm{PbI}_{2}\right) / \mathrm{CVD}(\mathrm{MAI})$.

Proof-of-concept devices. Based on the results presented above, $T_{\text {substrate }}$ and $T_{\text {crucible }}$ are set between $120-140{ }^{\circ} \mathrm{C}$ and $200-210{ }^{\circ} \mathrm{C}$, respectively. In these CVD conditions, a full conversion of the $\mathrm{PbI}_{2}$ template to the perovskite alpha phase is achieved after 2 to 3 hours of evaporation without forming the hydrated phase based on XRD and UV-Visible-near infrared (UV-VisNIR) absorptance data (Figure S8).
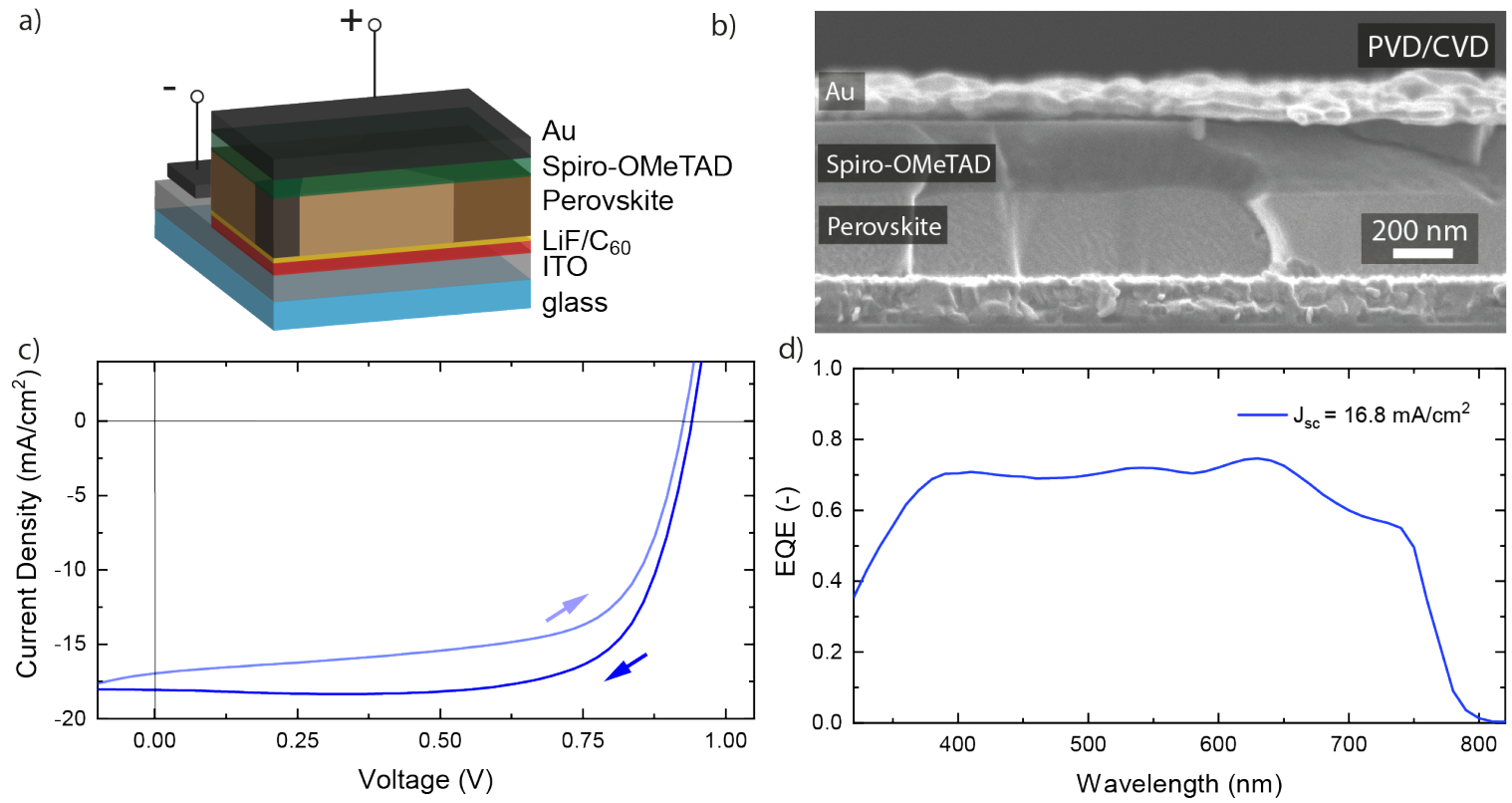

Figure 5: a) Schematic view of the perovskite cell, b) cross-section SEM image of a perovskite solar cell produced with the PVD/CVD technique, c) best forward and reverse $J$ - $V$ curves from a perovskite solar cell produced by $\mathrm{PVD} / \mathrm{CVD}, \mathrm{d}$ ) corresponding external quantum efficiency (EQE) spectrum.

Perovskite solar cells in the n-i-p configuration are then produced to assess the layer quality in devices. First, $1 \mathrm{~nm}$ of $\mathrm{LiF}$ and $6 \mathrm{~nm}$ of $\mathrm{C}_{60}$ are thermally evaporated on top of glass/ITO substrates. Then, $150 \mathrm{~nm}$ of $\mathrm{PbI}_{2}$ is thermally evaporated in a high vacuum chamber with a deposition rate of $1 \AA / \mathrm{s}$. This template is converted to the perovskite phase by a CVD of MAI as described above $\left(T_{\text {crucible }}=200\right.$ or $210^{\circ} \mathrm{C}$, carrier gas flow rate of $800 \mathrm{sccm}, T_{\text {substrate }}=120$ or $140{ }^{\circ} \mathrm{C}, T_{\text {preheating }}=150{ }^{\circ} \mathrm{C}, T_{\text {gas line }}=200{ }^{\circ} \mathrm{C}$, pressure $=12 \mathrm{mbar}$, duration $\left.=1 \mathrm{~h}-3 \mathrm{hrs}\right)$. The 
samples are transferred to a nitrogen-filled glovebox, washed by isopropanol (IPA) and dried for $5 \mathrm{~min}$ at $100^{\circ} \mathrm{C}$ using a hotplate to remove any excess of MAI that may have built up on the perovskite surface. IPA washing is performed solely with layers destined for cells to avoid a possible formation of the non-photoactive hydrated phase discussed above. A solution of doped-Spiro-OMeTAD dissolved in chlorobenzene is then spin-coated at $4000 \mathrm{rpm}$ for $30 \mathrm{~s}$. Finally, $100 \mathrm{~nm}$ of gold is evaporated at a rate of $1 \AA / \mathrm{s}$. A sketch of the device structure and a SEM cross-section image of the perovskite solar cell are presented in Figure 5a-b.

Current density-voltage $(J-V)$ parameters of perovskite solar cells fabricated using this hybrid PVD/CVD process with $T_{\text {substrate }}=120^{\circ} \mathrm{C}$ or $140{ }^{\circ} \mathrm{C}$ indicate that 2 hours of deposition leads to the best results (Figures S9 and S10). This is in good agreement with the characterisation results of bare perovskite layers, where shorter deposition durations $(60 \mathrm{~min})$ led to unreacted $\mathrm{PbI}_{2}$ at these temperatures (Figure 4c). Furthermore, a $T_{\text {substrate }}$ of $140^{\circ} \mathrm{C}$ was found to give more reproducible results compared to a $T_{\text {substrate }}$ of $120^{\circ} \mathrm{C}$, regardless of the deposition duration (Figures S9 and S10). This difference is mainly attributed to the fact that a lower $T_{\text {substrate }}$ may lead to a slight MAI oversaturation and hydrated phase formation (Figure 4b-c), which might prevent charge carrier collection. ${ }^{42}$ Current-voltage $(J-V)$ scans and external quantum efficiency (EQE) measurements of a perovskite solar cell processed with the PVD/CVD method are presented in Figure 5c-d. A forward scan efficiency of $10.3 \%\left(V_{o c}=927 \mathrm{mV}, F F=65.4 \%, J_{s c}\right.$ $\left.=17.0 \mathrm{~mA} / \mathrm{cm}^{2}, \eta_{\text {reverse }}=12.3 \%\right)$ is obtained and co-processed PVD/CVD device efficiencies show an encouraging statistical distribution at the proof-of-concept stage (Figure S11 and Figure S12). Future optimisations will aim to remove hysteresis and improve efficiencies.

Large scale conformal coating of perovskite layers. Vapour-phase deposition methods should enable to homogenously coat larger areas compared to spin coating, ${ }^{6,43}$ as hinted by several CVD studies. ${ }^{12,25}$ Perovskite layers deposited by PVD/CVD over an area of up to $100 \mathrm{~cm}^{2}$ (in a tube furnace) have been reported..$^{27,44}$ The vapour transport deposition system presented here also enables depositions over large areas, as highlighted by the SEM cross-sectional images of MAI deposited at low $T_{\text {substrate }}$ (OVPD regime) on a 6inch c-Si wafer (corresponding to $239 \mathrm{~cm}^{2}$, Figure S13). While some local roughness resulting from the growth mechanism of MAI can be noticed, a similar thickness is measured across the full 6-inch c-Si wafer. Homogenous perovskite layers are then demonstrated over 15 x $15 \mathrm{~cm}^{2}$ glass substrates by exposing a 150 nm-thick $\mathrm{PbI}_{2}$ template to MAI vapours ( $T_{\text {substrate }}$ and $T_{\text {crucible }}$ of $120^{\circ} \mathrm{C}$ and $200{ }^{\circ} \mathrm{C}$, respectively, Figure 6a). As shown in Figure S14, a thickness difference of $8 \%_{\text {rel }}$ is measured by profilometry 
across this area, a difference that mainly comes from the inhomogeneity of the PVD step. X-ray diffraction patterns acquired at the centre, middle and edge of the substrate confirm the presence of a pure $\mathrm{MAPbI}_{3}$ layer across the substrate (Figure $6 \mathbf{b}$ ).

a)

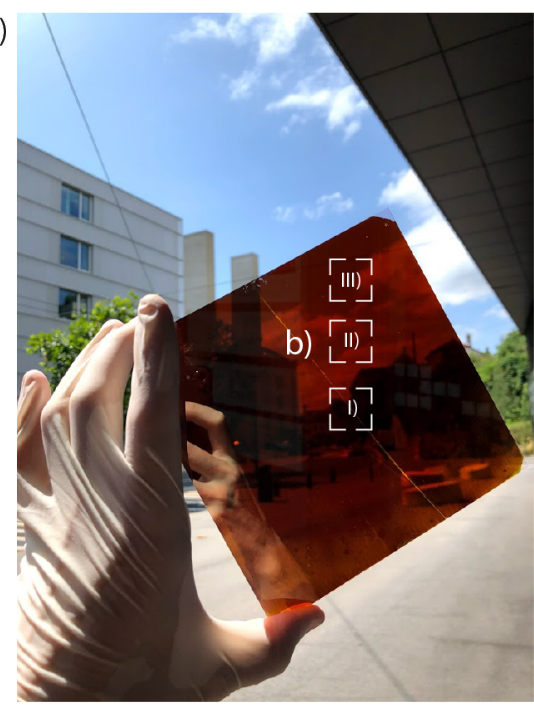

c)

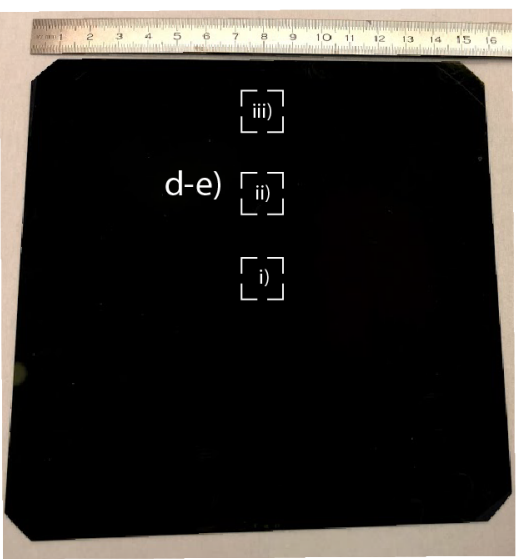

e) b)

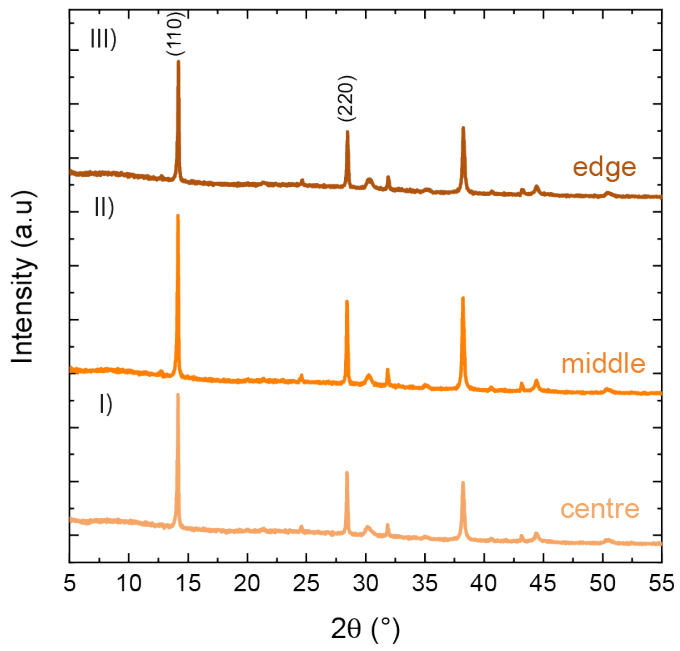

d)

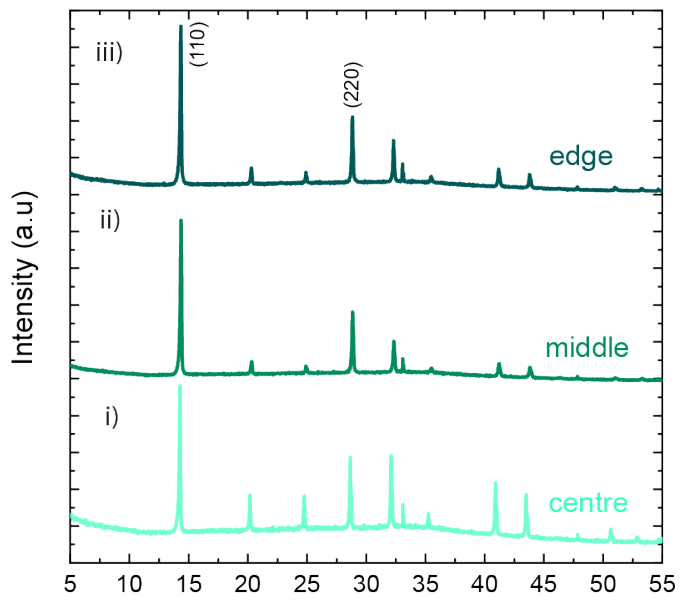

$2 \theta\left({ }^{\circ}\right)$

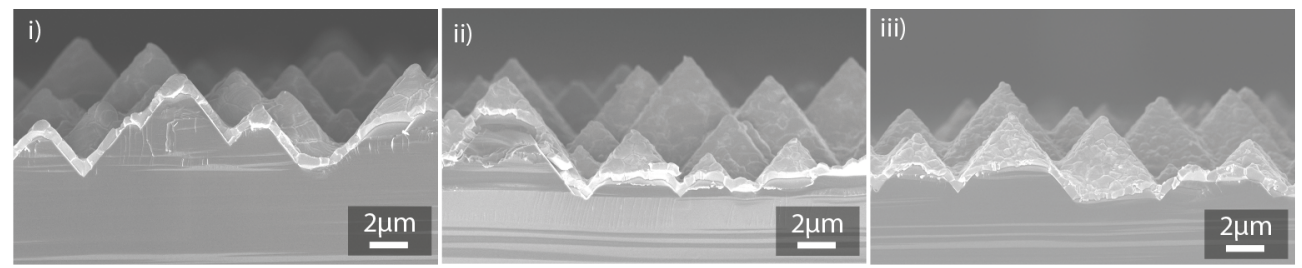

Figure 6: a) Picture of a perovskite layer deposited on a $15 \times 15 \mathrm{~cm}^{2}$ glass/ITO substrate by $\mathrm{PVD} / \mathrm{CVD}, \mathrm{b}) \mathrm{X}$-ray diffractograms of the perovskite film measured at the centre (I), middle (II) and edge (III) of the $15 \times 15 \mathrm{~cm}^{2}$ perovskite layer shown in a), c) picture of the perovskitecoated 6-inch c-Si wafer, d) corresponding X-ray diffractograms measured at the centre (i), middle (ii) and edge (iii) of the wafer, and e) cross-section SEM image acquired at the centre (i), middle (ii) and edge (iii) of the wafer. 
In addition to large-area deposition, vapour-based deposition approaches enable conformal coating of various substrate textures, ${ }^{5,44,45}$ a promising feature in view of designing perovskite/c-Si tandems featuring textured bottom cells for optimal light management. ${ }^{5}$ Figure $6 \mathbf{c}$ shows a picture of a perovskite layer grown on such a $\mathrm{KOH}-$ textured 6-inch c-Si wafer. X-ray diffractograms and SEM cross-section images taken at different locations of the wafer confirm the conformal deposition of a fully converted perovskite layer (Figure 6 d-e). These results emphasise the suitability of this deposition process combining and PVD and CVD to produce perovskite layers over large areas and on pyramidal c-Si textures.

\section{CONCLUSION}

This study details a showerhead-based vapour transport deposition system that enables the deposition of the organic precursor of metal-halide perovskite absorbers. The system is able, over large areas and on pyramidal c-Si textures, to convert a $\mathrm{PbI}_{2}$ template to a photoactive $\mathrm{MAPbI}_{3}$ perovskite phase through an exposure to MAI vapours. This system decorrelates the precursor evaporation conditions from the deposition ones, providing a wider processing window compared to conventional tube furnaces. A wide range of optical, microstructural, crystallographic and chemical characterisation techniques were combined to identify the optimum evaporation, gas transport and deposition conditions. Absorbers processed by converting a thermally evaporated $\mathrm{PbI}_{2}$ template to the perovskite phase by CVD were included in proof-of-concept solar cells $\left(0.25 \mathrm{~cm}^{2}\right)$. Importantly, this system yields homogenous perovskite layers on large areas, as demonstrated with $225 \mathrm{~cm}^{2}$ glass/ITO substrates and $239 \mathrm{~cm}^{2}$ (6-inch) c-Si wafers textured by $\mathrm{KOH}$-etching, an important step towards the fabrication of perovskite cells with industry-relevant active areas.

ASSOCIATED CONTENT

\section{Supporting Information}


Overview of the VTD setup; Table of the main FTIR vibrational modes of MAI; TGA and DSC analysis of MAI; Liquid ${ }^{1} H$ NMR of the MAI powder remaining in the crucible; Carrier gas temperature profile; XRD of oversaturated perovskite phases; XRD of the $\mathrm{PbI}_{2}$ templates with different crucible temperatures; AFM images of the perovskite layers; XRD and UV-vis-NIR data of the perovskite layer over time; J-V parameters with $T_{\text {substrate }}$ at $120^{\circ} \mathrm{C}$ and $140^{\circ} \mathrm{C}$; Statistical efficiency distribution of perovskite solar cells by the PVD/VTD method; Large-scale MAI deposition on a 6-inch wafer: $\mathrm{PbI}_{2}$ and perovskite layer homogeneities on a $15 \times 15$ $\mathrm{cm}^{2}$ glass/ITO substrate.

\section{AUTHOR INFORMATION:}

\section{Corresponding Author}

Florent Sahli - Ecole Polytechnique Fédérale de Lausanne (EPFL), Institute of Microengineering (IMT), Photovoltaics and Thin-Film Electronics Laboratory, Rue de la Maladière 71b, 2002 Neuchâtel, Switzerland; Email: florent.sahli@epfl.ch

\section{Authors}

Nathanaël Miaz - Centre Suisse d'électronique et de microtechnique (CSEM), PV-Center, Jaquet-Droz 1, 2002 Neuchâtel, Switzerland.

Niccolò Salsi - Ecole Polytechnique Fédérale de Lausanne (EPFL), Institute of Microengineering (IMT), Photovoltaics and Thin-Film Electronics Laboratory, Rue de la Maladière 71b, 2002 Neuchâtel, Switzerland.

Cédric Bucher - Ecole Polytechnique Fédérale de Lausanne (EPFL), Institute of Microengineering (IMT), Photovoltaics and Thin-Film Electronics Laboratory, Rue de la Maladière 71b, 2002 Neuchâtel, Switzerland.

Aymeric Schafflützel - Ecole Polytechnique Fédérale de Lausanne (EPFL), Institute of Microengineering (IMT), Photovoltaics and Thin-Film Electronics Laboratory, Rue de la Maladière 71b, 2002 Neuchâtel, Switzerland. 
Quentin Guesnay - Ecole Polytechnique Fédérale de Lausanne (EPFL), Institute of Microengineering (IMT), Photovoltaics and Thin-Film Electronics Laboratory, Rue de la Maladière 71b, 2002 Neuchâtel, Switzerland.

Léo Duchêne - Swiss Federal Laboratories for Materials Science and Technology (EMPA), Laboratory Materials for Energy Conversion, 8600 Dübendorf, Switzerland.

Bjoern Niesen - Ecole Polytechnique Fédérale de Lausanne (EPFL), Institute of Microengineering (IMT), Photovoltaics and Thin-Film Electronics Laboratory, Rue de la Maladière 71b, 2002 Neuchâtel, Switzerland.

Centre Suisse d'électronique et de microtechnique (CSEM), PV-Center, Jaquet-Droz 1, 2002 Neuchâtel, Switzerland.

Christophe Ballif - Ecole Polytechnique Fédérale de Lausanne (EPFL), Institute of Microengineering (IMT), Photovoltaics and Thin-Film Electronics Laboratory, Rue de la Maladière 71b, 2002 Neuchâtel, Switzerland.

Centre Suisse d'électronique et de microtechnique (CSEM), PV-Center, Jaquet-Droz 1, 2002 Neuchâtel, Switzerland.

Quentin Jeangros - Ecole Polytechnique Fédérale de Lausanne (EPFL), Institute of Microengineering (IMT), Photovoltaics and Thin-Film Electronics Laboratory, Rue de la Maladière 71b, 2002 Neuchâtel, Switzerland.

\section{Notes}

The authors declare no competing financial interest.

\section{ACKNOWLEDGMENTS:}

The authors would like to acknowledge financial supports from the Swiss Federal Office of Energy (SI/501804-01 INTENT) and the Swiss National Science Foundation (176552 Bridge Power, CRSII5 171000 Sinergia Episode projet and the R'Equip project; Grant No. 206021_182981 “Ultrafast EBSD System on a new SEM”). The authors thank Aurélien Bornet for his help for the NMR experiments. 


\section{REFERENCES:}

1. Petrus, M. L. et al. Capturing the Sun: A Review of the Challenges and Perspectives of Perovskite Solar Cells. Adv. Energy Mater. 1700264, 1-27 (2017).

2. Haegel, N. M. et al. Terawatt-scale photovoltaics: Trajectories and challenges. Science. 356, 141-143 (2017).

3. NREL. Best Research-Cell Efficiencies Chart. Best Research-Cell Efficiencies Chart (2019).

4. Chen, Y., Zhang, L., Zhang, Y., Gao, H. \& Yan, H. Large-area perovskite solar cells - a review of recent progress and issues. RSC Adv. 8, 10489-10508 (2018).

5. Sahli, F. et al. Fully textured monolithic perovskite/silicon tandem solar cells with $25.2 \%$ power conversion efficiency. Nat. Mater. 17, 820-826 (2018).

6. Ávila, J., Momblona, C., Boix, P. P., Sessolo, M. \& Bolink, H. J. Vapor-Deposited Perovskites: The Route to High-Performance Solar Cell Production? Joule 1-12 (2017). doi:10.1016/j.joule.2017.07.014

7. Ono, L. K., Juarez-Perez, E. J. \& Qi, Y. Progress on Perovskite Materials and Solar Cells with Mixed Cations and Halide Anions. ACS Appl. Mater. Interfaces 9, 30197-30246 (2017).

8. Abzieher, T. et al. Efficient All-Evaporated pin-Perovskite Solar Cells: A Promising Approach Toward Industrial Large-Scale Fabrication. IEEE J. Photovoltaics 9, 12491257 (2019).

9. Li, H. et al. POCl3 diffusion for industrial Si solar cell emitter formation. Front. Energy 11, 42-51 (2017).

10. Aberle, A. G. Thin-film solar cells. Thin Solid Films 517, 4706-4710 (2009).

11. Longo, G. et al. Fully Vacuum Processed Wide Bandgap Mixed Halide Perovskite Solar Cells. ACS Energy Lett. 3, 214-219 (2018). 
12. Leyden, M. R. M. R., Jiang, Y. \& Qi, Y. Chemical vapor deposition grown formamidinium perovskite solar modules with high steady state power and thermal stability. J. Mater. Chem. A 4, 13125-13132 (2016).

13. Zhu, X. et al. Superior stability for perovskite solar cells with $20 \%$ efficiency using vacuum co-evaporation. Nanoscale 9, 12316-12323 (2017).

14. Li, J. et al. Highly Efficient Thermally Co-evaporated Perovskite Solar Cells and Minimodules. Joule 1-19 (2020). doi:10.1016/j.joule.2020.03.005

15. Borchert, J. et al. Structural investigation of co-evaporated methyl ammonium lead halide perovskite films during growth and thermal decomposition using different $\mathrm{PbX} 2$ (X = I, Cl) precursors. J. Mater. Chem. A 3, 19842-19849 (2015).

16. Ono, L. K., Wang, S., Kato, Y., Raga, S. R. \& Qi, Y. Fabrication of semi-transparent perovskite films with centimeter-scale superior uniformity by the hybrid deposition method. Energy Environ. Sci. 7, 3989-3993 (2014).

17. Borchert, J. et al. Impurity Tracking Enables Enhanced Control and Reproducibility of Hybrid Perovskite Vapour Deposition. ACS Appl. Mater. Interfaces acsami.9b07619 (2019). doi:10.1021/acsami.9b07619

18. Bækbo, M. J., Hansen, O., Chorkendorff, I. \& Vesborg, P. C. K. Deposition of methylammonium iodide: Via evaporation-combined kinetic and mass spectrometric study. RSC Adv. 8, 29899-29908 (2018).

19. Chen, Q. et al. Planar Heterojunction Perovskite Solar Cells via Vapor-Assisted Solution Process. J. Am. Chem. Soc. 136, 622-625 (2014).

20. Leyden, M. R. M. R. et al. High performance perovskite solar cells by hybrid chemical vapor deposition. J. Mater. Chem. A 2, 18742-18745 (2014).

21. Luo, P. et al. Uniform, Stable, and Efficient Planar-Heterojunction Perovskite Solar Cells by Facile Low-Pressure Chemical Vapor Deposition under Fully Open-Air Conditions. ACS Appl. Mater. Interfaces 7, 2708-2714 (2015).

22. Peng, Y., Jing, G. \& Cui, T. A hybrid physical-chemical deposition process at ultra-low 
temperatures for high-performance perovskite solar cells. J. Mater. Chem. A 3, 12436$12442(2015)$.

23. Yin, J. et al. Vapor-assisted crystallisation control toward high performance perovskite photovoltaics with over $18 \%$ efficiency in the ambient atmosphere. J. Mater. Chem. A 4, 13203-13210 (2016).

24. Leyden, M. R., Lee, M. V., Raga, S. R. \& Qi, Y. Large formamidinium lead trihalide perovskite solar cells using chemical vapor deposition with high reproducibility and tunable chlorine concentrations. J. Mater. Chem. A 3, 16097-16103 (2015).

25. Jiang, Y. et al. Combination of Hybrid CVD and Cation Exchange for Upscaling CsSubstituted Mixed Cation Perovskite Solar Cells with High Efficiency and Stability. $A d v$. Funct. Mater. 1703835 (2017). doi:10.1002/adfm.201703835

26. Luo, L. et al. Large-area perovskite solar cells with CsxFA1-xPbI3-yBry thin films deposited by a vapor-solid reaction method. J. Mater. Chem. A 6, 21143-21148 (2018).

27. Qiu, L. et al. Hybrid Chemical Vapor Deposition Enables Scalable and Stable Cs-FA Mixed Cation Perovskite Solar Modules with a Designated Area of $91.8 \mathrm{~cm} 2$ Approaching 10\% Efficiency. J. Mater. Chem. A 7, 6920-6929 (2019).

28. Tavakoli, M. M. et al. Fabrication of efficient planar perovskite solar cells using a onestep chemical vapor deposition method. Sci. Rep. 5, 14083 (2015).

29. Clark, C. P., Voigt, B., Aydil, E. S. \& Holmes, R. J. Carrier-gas assisted vapor deposition for highly tunable morphology of halide perovskite thin films. Sustain. Energy Fuels $\mathbf{3}$, 2447-2455 (2019).

30. Hoerantner, M. T. et al. High-Speed Vapor Transport Deposition of Perovskite Thin Films. ACS Appl. Mater. Interfaces 11, 32928-32936 (2019).

31. Stümmler, D. et al. Direct Chemical Vapor Phase Deposition of Organometal Halide Perovskite Layers. MRS Adv. 2, 1189-1194 (2017).

32. Sanders, S. et al. Showerhead-Assisted Chemical Vapor Deposition of Perovskite Films for Solar Cell Application. MRS Adv. (2020). doi:10.1557/adv.2020.126 
33. Sanders, S. et al. Chemical Vapor Deposition of Organic-Inorganic Bismuth-Based Perovskite Films for Solar Cell Application. Sci. Rep. 9, 1-8 (2019).

34. Forrest, S. R., Burrows, P. E., Stroustrup, A., Strickland, D. \& Ban, V. S. Intense second harmonic generation and long-range structural ordering in thin films of an organic salt grown by organic vapor phase deposition. Appl. Phys. Lett. 68, 1326-1328 (1996).

35. Rusu, M. et al. Organic donor, acceptor and buffer layers of small molecules prepared by OVPD technique for photovoltaics. Renew. Energy 33, 254-258 (2008).

36. Burrows, P. E. et al. Organic vapor phase deposition: a new method for the growth of organic thin films with large optical non-linearities. J. Cryst. Growth 156, 91-98 (1995).

37. Heuken, M. \& Meyer, N. Organic Vapor Phase Deposition. in Organic Electronics 10, 203-232 (Wiley-VCH Verlag GmbH \& Co. KGaA, 2006).

38. Patel, J. B., Milot, R. L., Wright, A. D., Herz, L. M. \& Johnston, M. B. Formation Dynamics of CH 3 NH 3 PbI 3 Perovskite Following Two-Step Layer Deposition. $J$. Phys. Chem. Lett. 7, 96-102 (2016).

39. Weber, O. J., Charles, B. \& Weller, M. T. Phase behaviour and composition in the formamidinium-methylammonium hybrid lead iodide perovskite solid solution. $J$. Mater. Chem. A 4, 15375-15382 (2016).

40. Van Gompel, W. T. M. et al. Degradation of the Formamidinium Cation and the Quantification of the Formamidinium-Methylammonium Ratio in Lead Iodide Hybrid Perovskites by Nuclear Magnetic Resonance Spectroscopy. J. Phys. Chem. C 122, 41174124 (2018).

41. Juarez-Perez, E. J., Hawash, Z., Raga, S. R., Ono, L. K. \& Qi, Y. Thermal degradation of $\mathrm{CH} 3 \mathrm{NH} 3 \mathrm{PbI} 3$ perovskite into $\mathrm{NH} 3$ and $\mathrm{CH} 3 \mathrm{I}$ gases observed by coupled thermogravimetry-mass spectrometry analysis. Energy Environ. Sci. 9, 3406-3410 (2016).

42. Lohmann, K. B. et al. Control over Crystal Size in Vapor Deposited Metal-Halide Perovskite Films. ACS Energy Lett. 710-717 (2020). doi:10.1021/acsenergylett.0c00183 
43. Swartwout, R., Hoerantner, M. T. \& Bulović, V. Scalable Deposition Methods for Largearea Production of Perovskite Thin Films. Energy Environ. Mater. 2, 119-145 (2019).

44. Hwang, J. et al. Conformal perovskite films on $100 \mathrm{~cm} 2$ textured silicon surface using two-step vacuum process. Thin Solid Films 693, 137694 (2020).

45. Cojocaru, L. et al. Detailed Investigation of Evaporated Perovskite Absorbers with High Crystal Quality on Different Substrates. ACS Appl. Mater. Interfaces 10, acsami.8b07999 (2018). 


\section{Vapour transport deposition of methylammonium iodide for perovskite solar cells}

Florent Sahli,,$^{*}$ Nathanaël Miaz, ${ }^{a, b}$ Niccolò Salsi, ${ }^{a}$ Cédric Bucher, ${ }^{a}$ Aymeric Schafflützel, ${ }^{a}$ Quentin Guesnay, ${ }^{a}$ Léo Duchêne, ${ }^{c}$ Bjoern Niesen, ${ }^{a, b,+}$ Christophe Ballif, ${ }^{a, b}$ Quentin Jeangros. ${ }^{a^{*}}$

${ }^{a}$ Ecole Polytechnique Fédérale de Lausanne (EPFL), Institute of Microengineering (IMT), Photovoltaics and Thin-Film Electronics Laboratory, Rue de la Maladière 71b, 2002 Neuchâtel, Switzerland.

b CSEM, PV-Center, Jaquet-Droz 1, 2002 Neuchâtel, Switzerland

c Empa, Swiss Federal Laboratories for Materials Science and Technology, Laboratory Materials for Energy Conversion, 8600 Dübendorf, Switzerland.

* Now at Empa, Swiss Federal Laboratories for Materials Science and Technology 8600 Dübendorf, Switzerland

* Corresponding authors

KEYWORDS: organohalide deposition, chemical vapour deposition, organic vapour phase deposition, organic-inorganic perovskite, large-scale vapour deposition.

\section{Supporting information}

\section{Vapour transport deposition setup}

The vapour transport deposition setup consists in an evaporation unit (containing the crucible and its heating system, a gas inlet and outlet, and a thermocouple attached to the crucible) and the deposition chamber (featuring a temperature-controlled substrate holder and a showerhead at the gas inlet). The evaporator and chamber are connected by a gas transport line. The exhaust of the chamber is connected to a dry pump via a butterfly valve, which enables pressure regulation of the system (from 3.7 to 12 mbar). In addition, a cold trap is placed before the butterfly valve to condense any residual organic vapours to protect the pump. The different components of the system are briefly described below. 

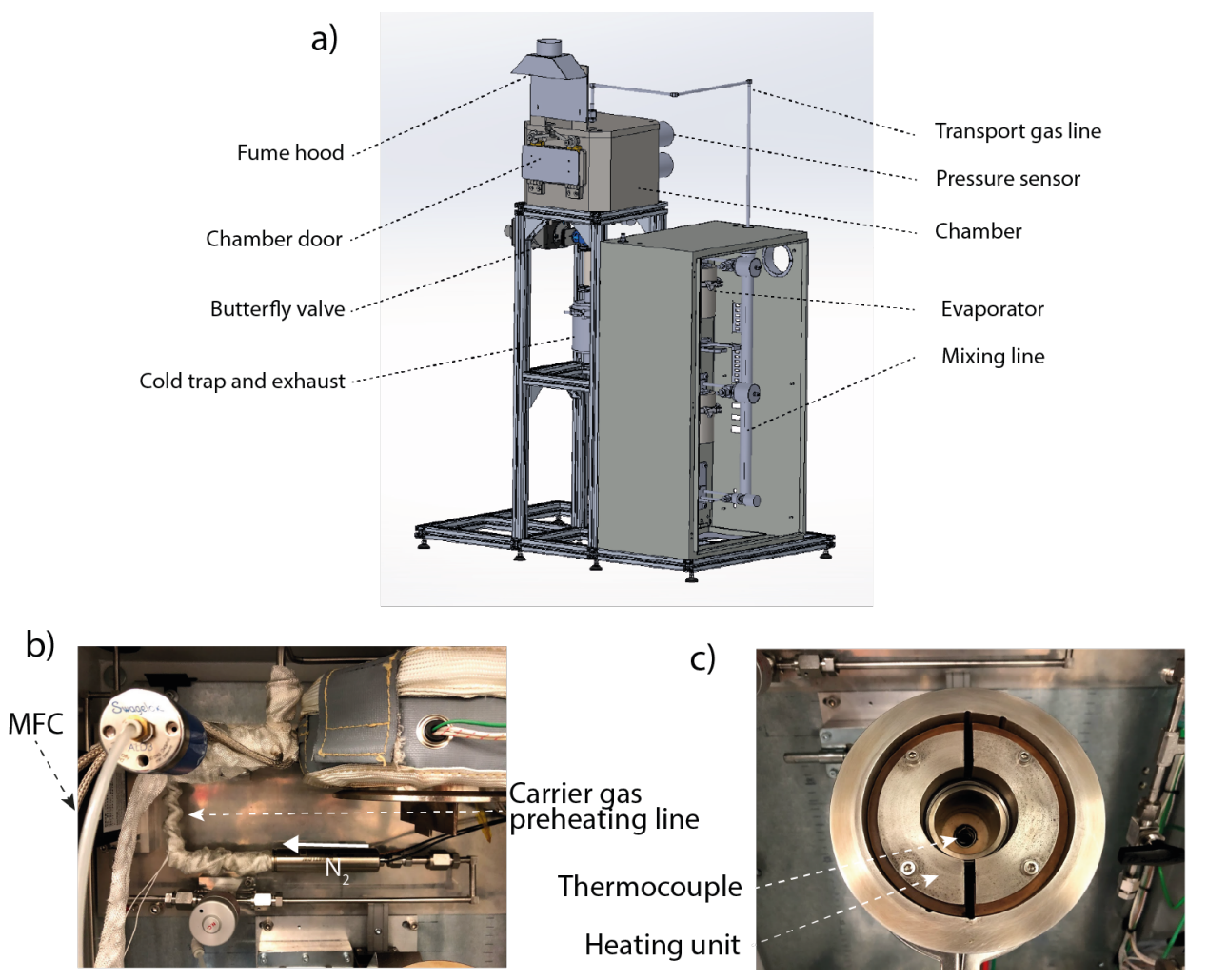

d)

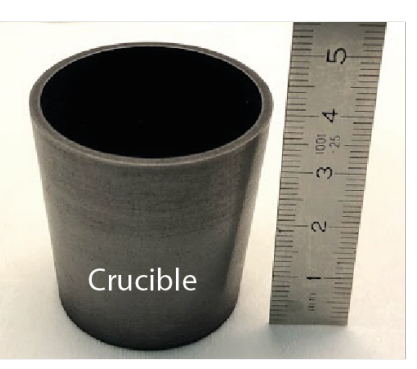

f)

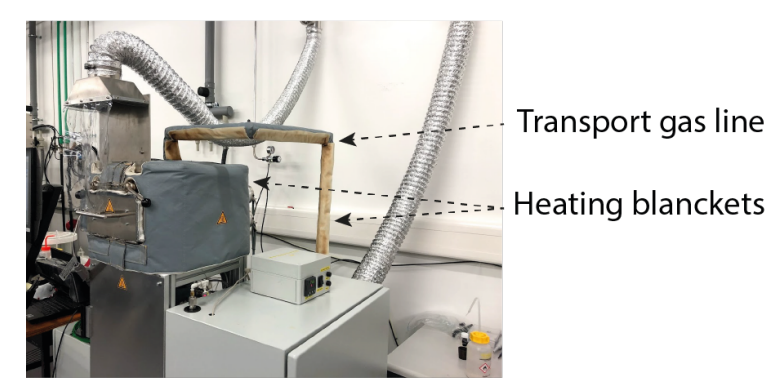

h)

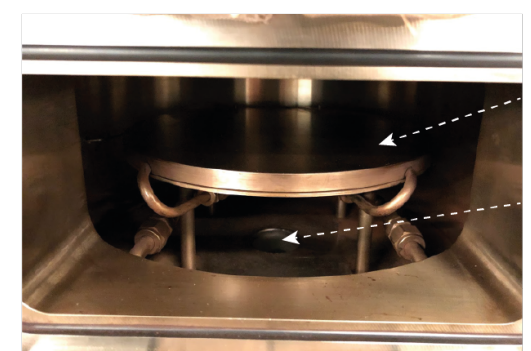

e)

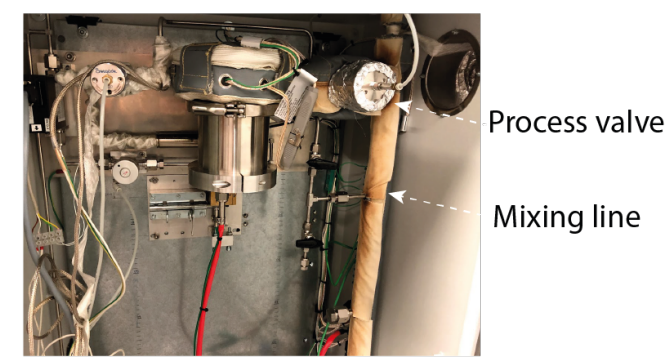

g)

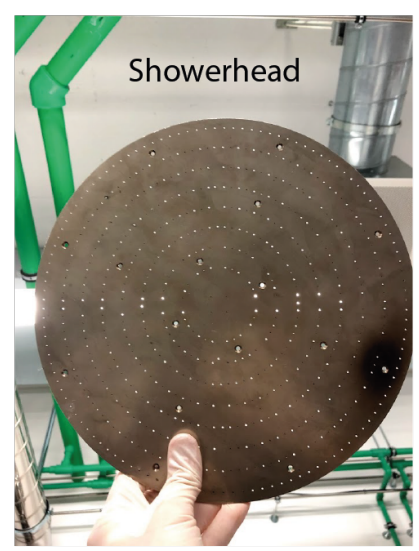

i)

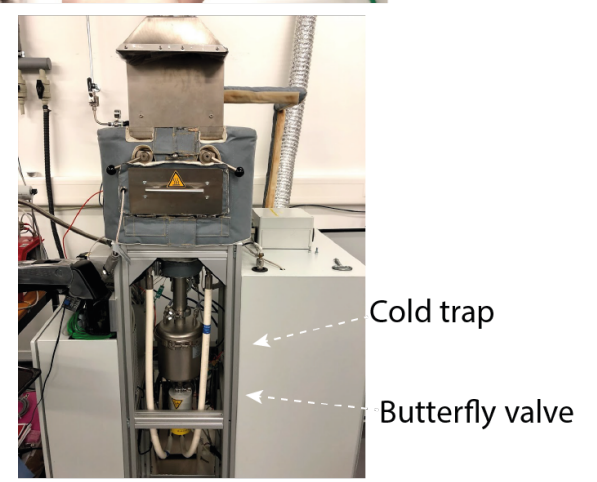


Figure S1: a) Overview of the setup and b) picture of the carrier gas preheating unit upstream of the evaporator, c) the evaporation unit, d) picture of the graphite crucible, e) overall picture of the carrier gas preheating unit, evaporator and mixing line, f) a side-view of the system with the gas transport line, g) picture of the showerhead, h) a view of the chamber with the deposition table and exhaust, i) the front of the VTD system with the cold trap and butterfly valve.

Carrier gas inlet: $\mathrm{N}_{2}$ is used as a carrier gas to drive the evaporated organic vapours from the evaporator into the deposition chamber. A mass flow controller (MFC) regulates the carrier gas flow. A carrier gas preheating unit consisting in a tubular heating coil and thermal heating blankets that enable to modify the temperature of the carrier gas upstream of the evaporator (up to a set point of $150{ }^{\circ} \mathrm{C}$, Figures S1b and S4).

Evaporator: evaporation is carried out in a graphite crucible containing $\sim 1 \mathrm{~g}$ of MAI. The temperature of the crucible is continuously monitored by a thermocouple directly in contact with the bottom of the crucible. The crucible heating unit consists in a cylindrical stainless steel tube that envelops the crucible. The heating coil is placed inside the stainless steel tube. The upper part of the evaporator is enveloped in heating blankets to prevent organohalide condensation (Figure S1c-e).

Gas transport line: the pipes connecting the evaporator to the chamber can be heated up to 200 ${ }^{\circ} \mathrm{C}$ thanks to a heating blanket (Figure S1f)

Chamber: organohalide vapours carried by $\mathrm{N}_{2}$ are forced through a showerhead to improve the homogeneity of the deposition (showerhead at $170{ }^{\circ} \mathrm{C}$ when chamber walls are at $200{ }^{\circ} \mathrm{C}$, Figure S1g). The temperature of the deposition table (Figure S1h) can be modulated via an oil circuit (from $25{ }^{\circ} \mathrm{C}$ to $180{ }^{\circ} \mathrm{C}$, controlled by a thermocouple). The deposition chamber walls can be heated thanks to a heating blanket (from $25^{\circ} \mathrm{C}$ to $200{ }^{\circ} \mathrm{C}$ ). When the blankets are set to $200^{\circ} \mathrm{C}$, the temperature measured on the inner side of the chamber reaches $\sim 170{ }^{\circ} \mathrm{C}$. The temperature of the heating blankets are set to $200{ }^{\circ} \mathrm{C}$ throughout this manuscript unless stated otherwise.

Exhaust: the exhaust of the chamber is directly located beneath the deposition table (Figure $\mathrm{S} 1 \mathrm{~h}$ ) and a trap cooled by a water circuit is placed after the chamber to condense the residual organohalides (Figure S1i). A butterfly valve is placed after the cold trap to regulate the pressure of the system. Finally, a dry pump is attached to the system. 


\begin{tabular}{|l|l|l|l|}
\hline Bond & Vibrational mode & From literature & This work \\
& & Wavenumber $\left(\mathrm{cm}^{-1}\right)$ & Wavenumber $\left(\mathrm{cm}^{-1}\right)$ \\
\hline${\mathrm{N}-\mathrm{H}_{3}}$ & stretching & $3080($ asym $) / / 2993(\mathrm{sym})$ & 3091 \\
\hline $\mathrm{C}-\mathrm{H}_{3} / \mathrm{N}-\mathrm{H}_{3}$ & bending & $1486(\mathrm{sym}), 1563(\mathrm{as})$ & $-\left(\mathrm{H}_{2} \mathrm{O}\right.$ peaks $)$ \\
\hline $\mathrm{C}-\mathrm{H}$ & rocking & 1252 & 1244 \\
\hline $\mathrm{C}-\mathrm{H}_{3} / \mathrm{N}-\mathrm{H}_{3}$ & stretching & $2963($ asym) $) / / 2912(\mathrm{sym})$ & $2963($ asym $)$ \\
& & & $-\left(\mathrm{H}_{2} \mathrm{O}\right.$ peaks $)$ \\
\hline $\mathrm{C}-\mathrm{N}$ & becking & 912 & 915 \\
\hline
\end{tabular}

Table S1: FTIR main vibrational modes of MAI based on literature data and measured in this work. ${ }^{4,38} \mathrm{C}-\mathrm{H}$ and $\mathrm{N}-\mathrm{H}$ bending at $1400-1500 \mathrm{~cm}^{-1}$ could not be identified due to the presence of the $\mathrm{H}_{2} \mathrm{O}$ vibration peaks. 


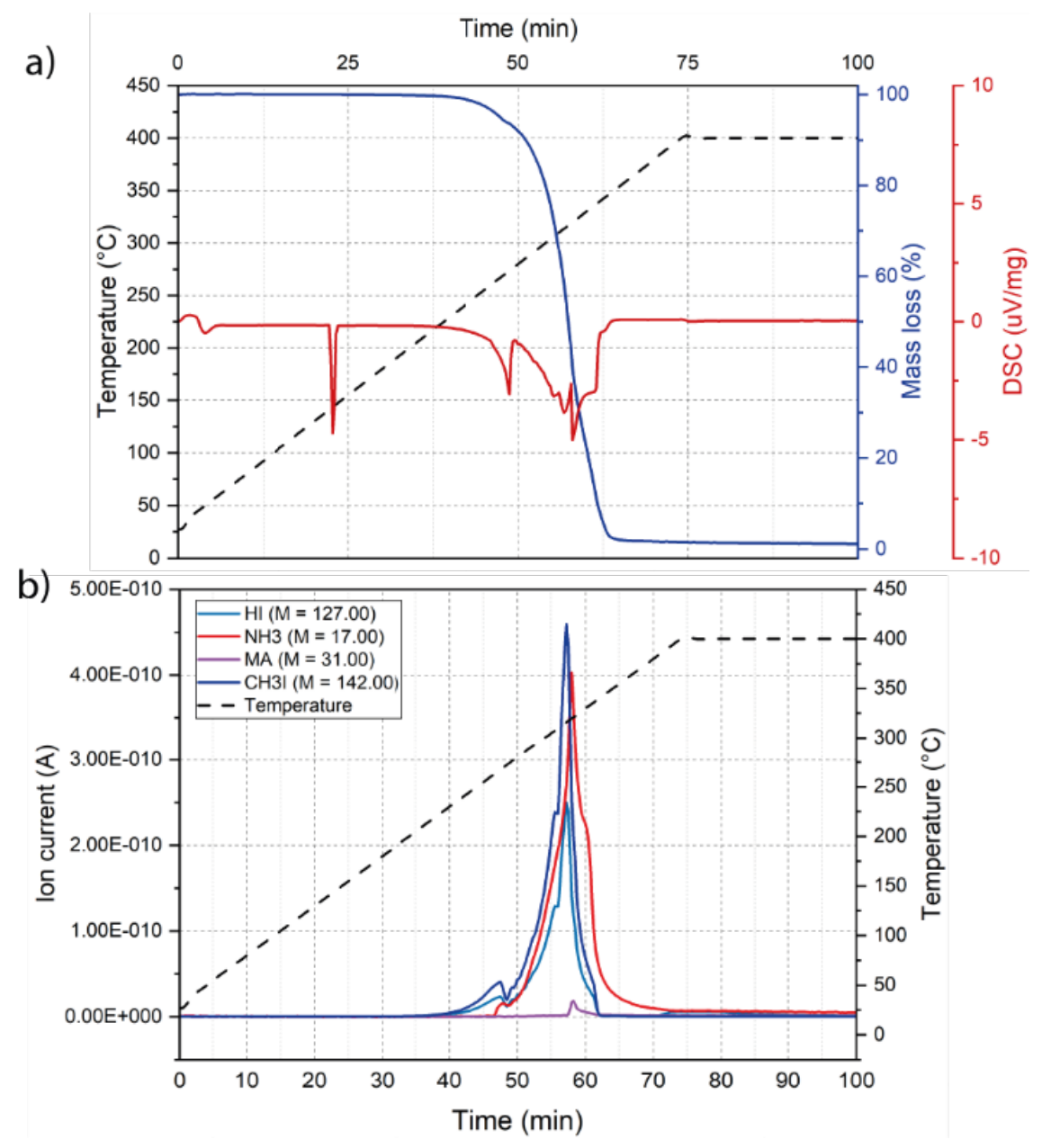

Figure S2: a) TGA and DSC analysis of MAI $\left(25-400{ }^{\circ} \mathrm{C}\right)$, b) mass spectrometry analysis showing the major fragments observed during MAI evaporation $\left(25-400{ }^{\circ} \mathrm{C}\right)$. 
a)
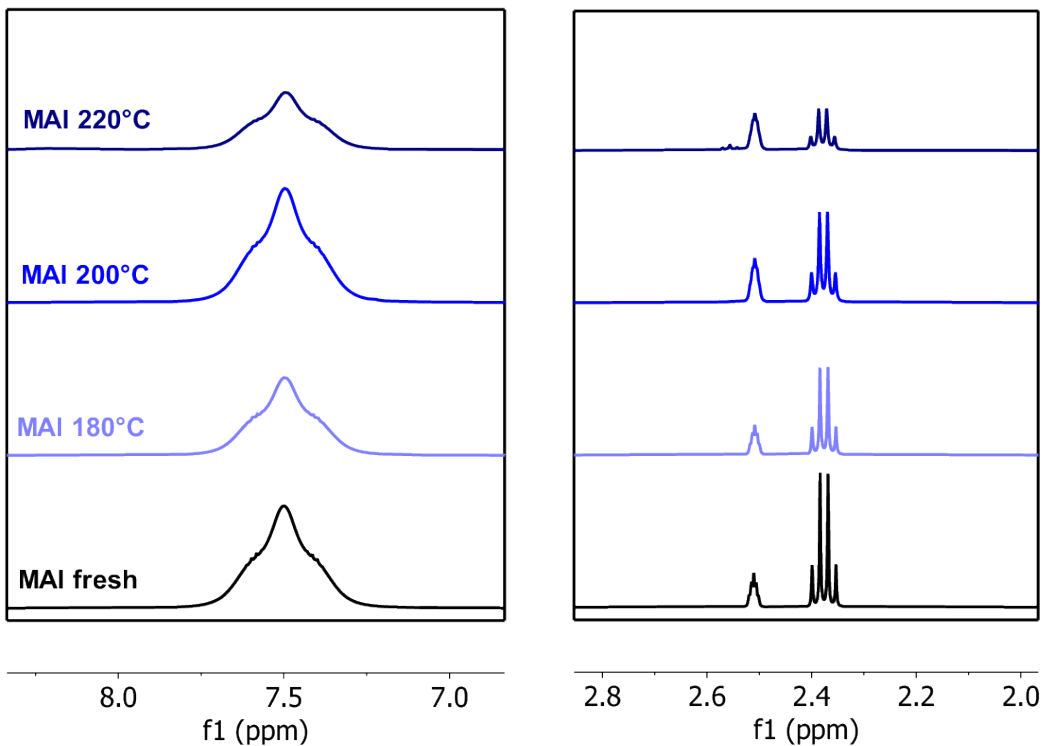

b)
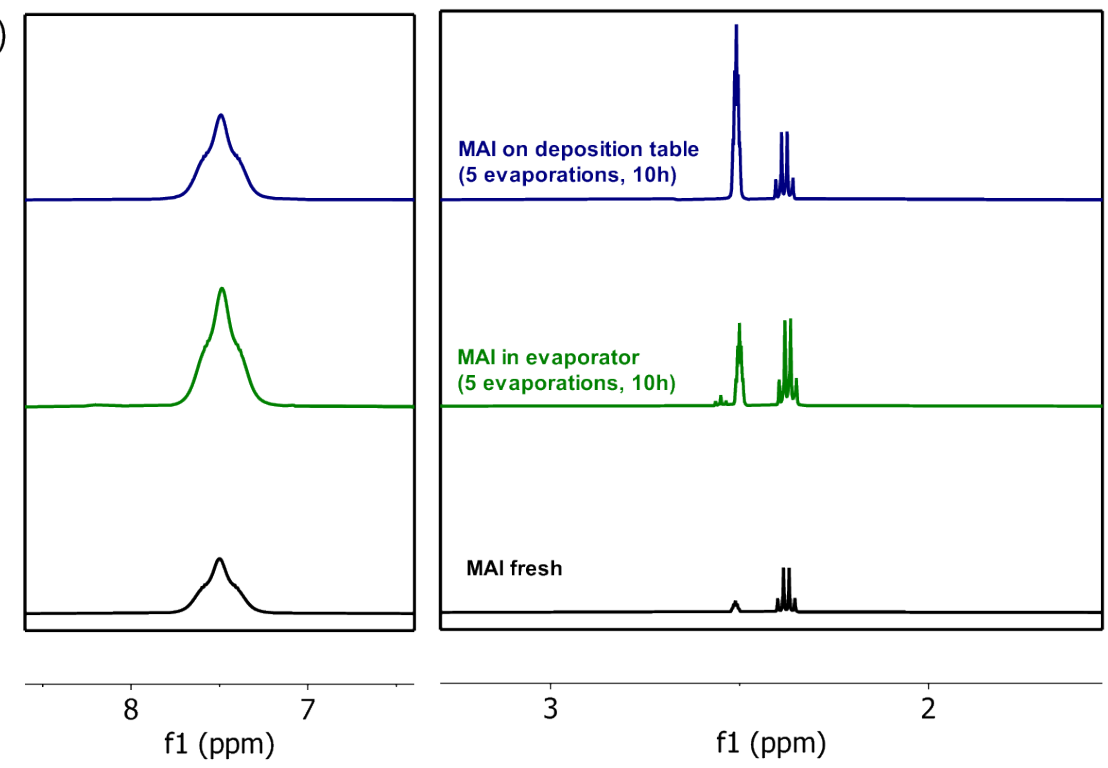

Figure S3: a) Liquid ${ }^{1} \mathrm{H}$ NMR of the MAI powder remaining in the crucible after depositing at a carrier gas flow of $800 \mathrm{sccm}$ and a working pressure of 4 mbar for 2 hours with different $T_{\text {crucible. }}$ A zoom on the $\mathrm{NH}_{3}$ peak $(7.5 \mathrm{ppm})$ is shown in the left insets, while $\mathrm{CH}_{3}$ peaks $(2.4$ ppm, the peak at $2.5 \mathrm{ppm}$ is the DMSO-6d peak) are shown in the right insets, b) Liquid ${ }^{1} \mathrm{H}$ NMR of the fresh MAI powder, MAI left in the crucible after 5 depositions with a $T_{\text {crucible }}$ of $200{ }^{\circ} \mathrm{C}$ (carrier gas flow rate $=800 \mathrm{sccm}$, working pressure $=4$ mbar, total duration $>600 \mathrm{~min}$ ) and the corresponding MAI deposited on the deposition table. 


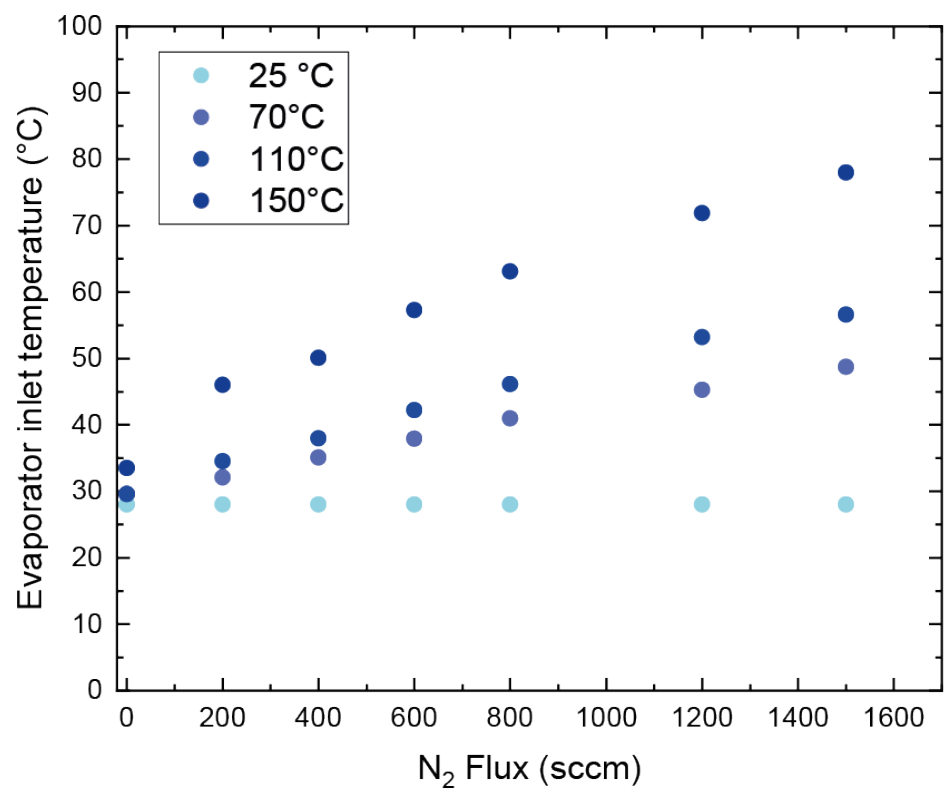

Figure S4: Evaporator inlet temperature as a function of the gas flow rate and temperature set point of the carrier gas preheating blanket ( $\left.T_{\text {preheating }}\right)$.
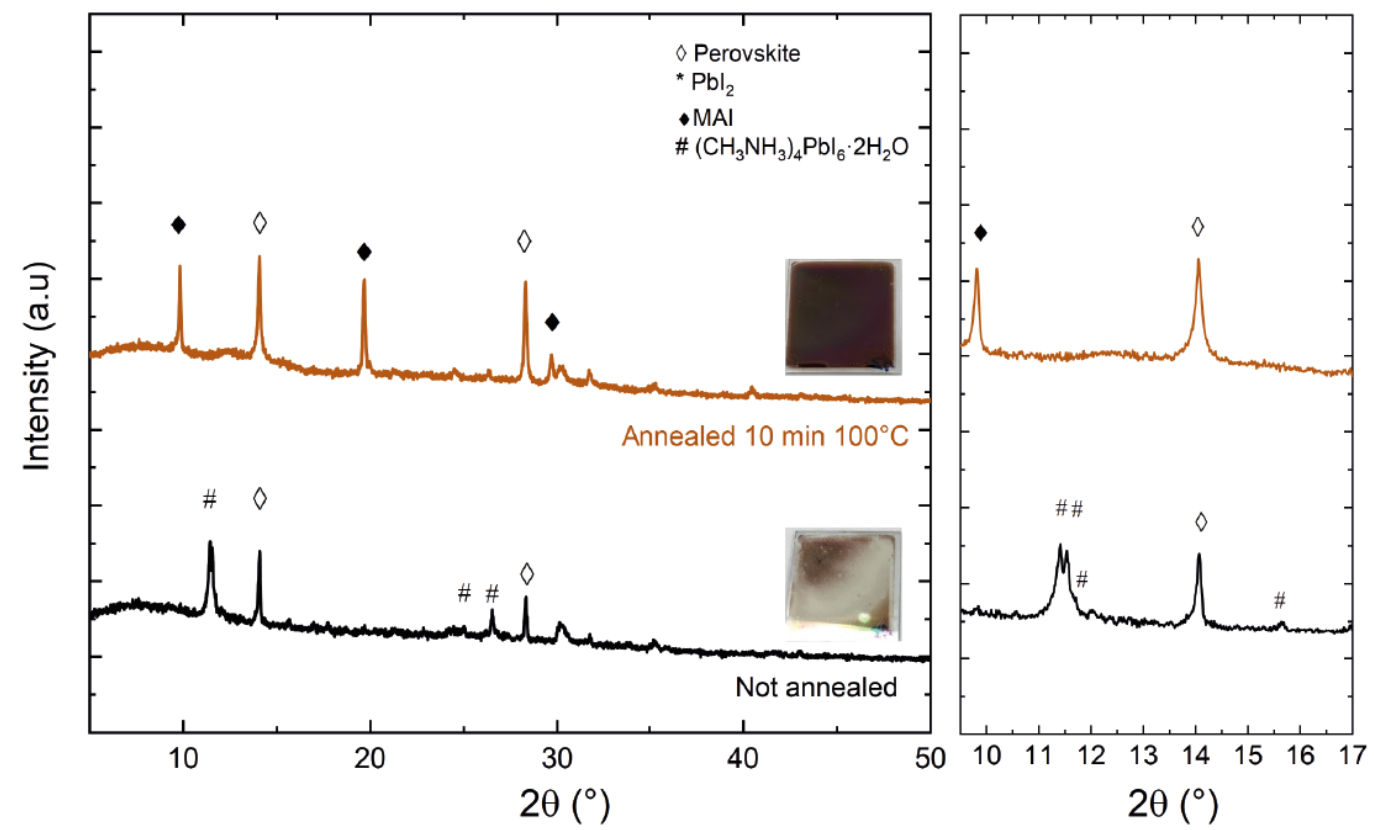

Figure S5 X-ray diffractograms of a $\mathrm{PbI}_{2}$ layer oversaturated with MAI, leading to the formation of a hydrated $\left(\mathrm{CH}_{3} \mathrm{NH}_{3}\right)_{4} \mathrm{PbI}_{6} \cdot 2 \mathrm{H}_{2} \mathrm{O}$ phase (bottom curve). Annealing the film for $10 \mathrm{~min}$ at 100 ${ }^{\circ} \mathrm{C}$ converts this hydrated phase to a mixture of perovskite and MAI phases (top curve). The inset on the right side provides a magnified view of the low diffraction angle range. 

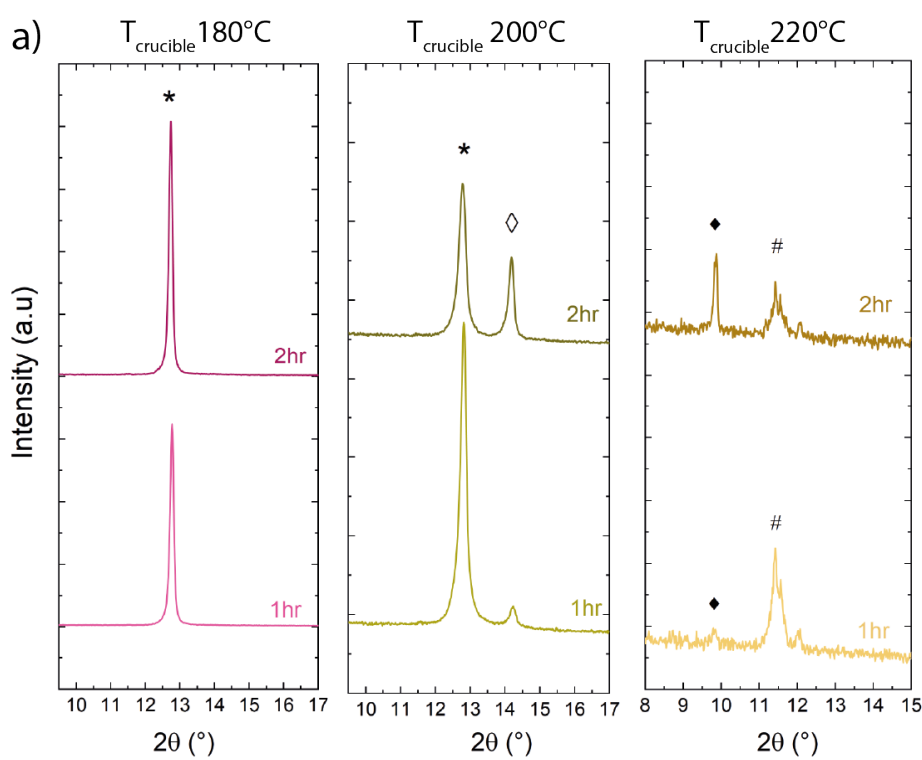

b)

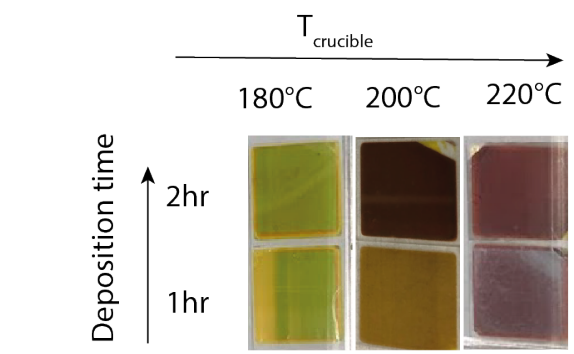

$\diamond$ Perovskite

* $\mathrm{Pbl}_{2}$

- MAI

$\#\left(\mathrm{CH}_{3} \mathrm{NH}_{3}\right)_{4} \mathrm{Pbl}_{6} \cdot 2 \mathrm{H}_{2} \mathrm{O}$

$2 \theta\left(^{\circ}\right)$

$2 \theta\left({ }^{\circ}\right)$

$2 \theta\left({ }^{\circ}\right)$

Figure S6: a) X-ray diffractograms of the $\mathrm{PbI}_{2}$ templates at a $T_{\text {substrate }}$ of $70{ }^{\circ} \mathrm{C}$ and exposed to MAI vapours evaporated at different $T_{\text {crucible }}\left(180^{\circ} \mathrm{C}, 200^{\circ} \mathrm{C}, 220^{\circ} \mathrm{C}\right)$ and for different durations (1 to 2 hours), b) pictures of the corresponding perovskite layers (carrier gas flow of $800 \mathrm{sccm}$, working pressure of 12 mbar). 

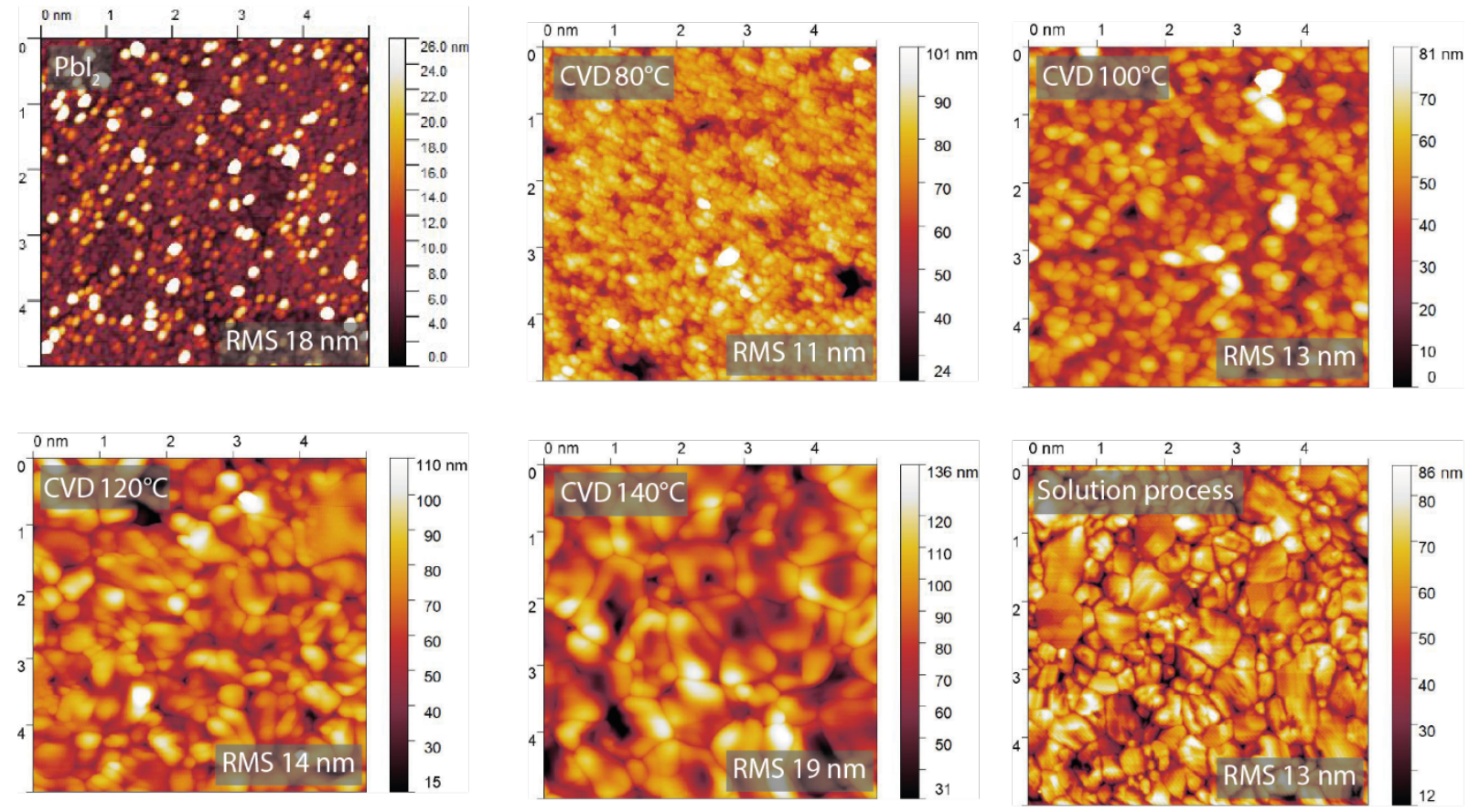

Figure S7: AFM images of the $\mathrm{PbI}_{2}$ and perovskite layers deposited by CVD at $T_{\text {substrate }}$ of 80 ${ }^{\circ} \mathrm{C}, 100{ }^{\circ} \mathrm{C}, 120{ }^{\circ} \mathrm{C}, 140{ }^{\circ} \mathrm{C}$, respectively. The last inset shows a perovskite layer, which was formed by spin coating MAI on the $\mathrm{PbI}_{2}$ template and a subsequent annealing step.
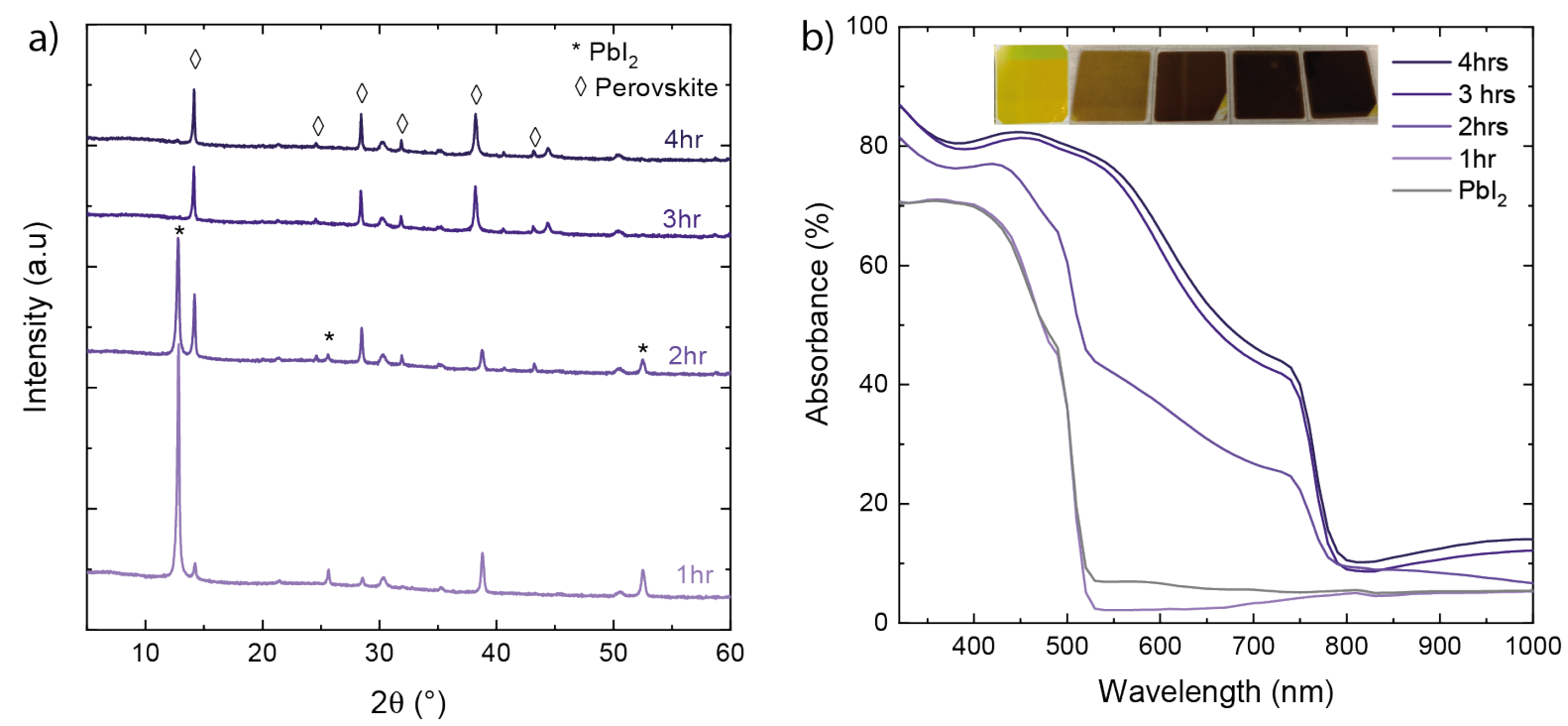

Figure S8 a) X-ray diffractograms of the perovskite formation with time, b) UV-vis-NIR absorptance of the corresponding layers. Deposition conditions: $T_{\text {substrate }}$ of $130{ }^{\circ} \mathrm{C}$ for different durations (1 to 4 hours), $T_{\text {crucible }}$ of $200{ }^{\circ} \mathrm{C}$, carrier gas flow of $800 \mathrm{sccm}$, working pressure of 12 mbar. 

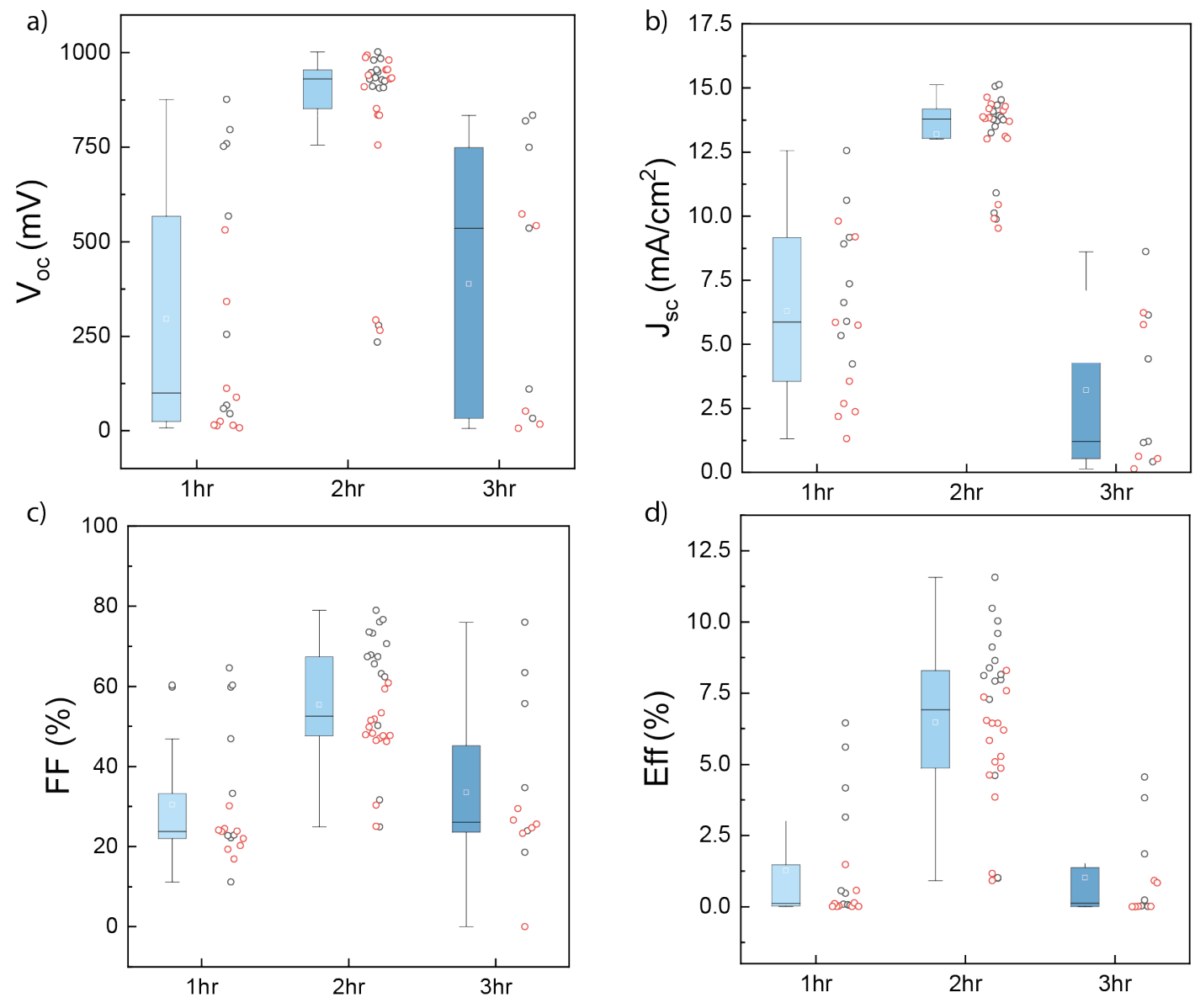

Figure S9: $J-V$ parameters (9-12 cells per condition, reverse and forward scans are displayed) of cells produced by PVD/CVD with $T_{\text {crucible }}=200{ }^{\circ} \mathrm{C}$ and $T_{\text {substrate }}=120^{\circ} \mathrm{C}$ for an evaporation duration of 1 to 3 hours. a) Open-circuit voltage $\left(V_{\mathrm{oc}}\right)$, b) short circuit current density $\left(J_{\mathrm{sc}}\right)$, c) fill factor (FF) and d) efficiency (Eff). 

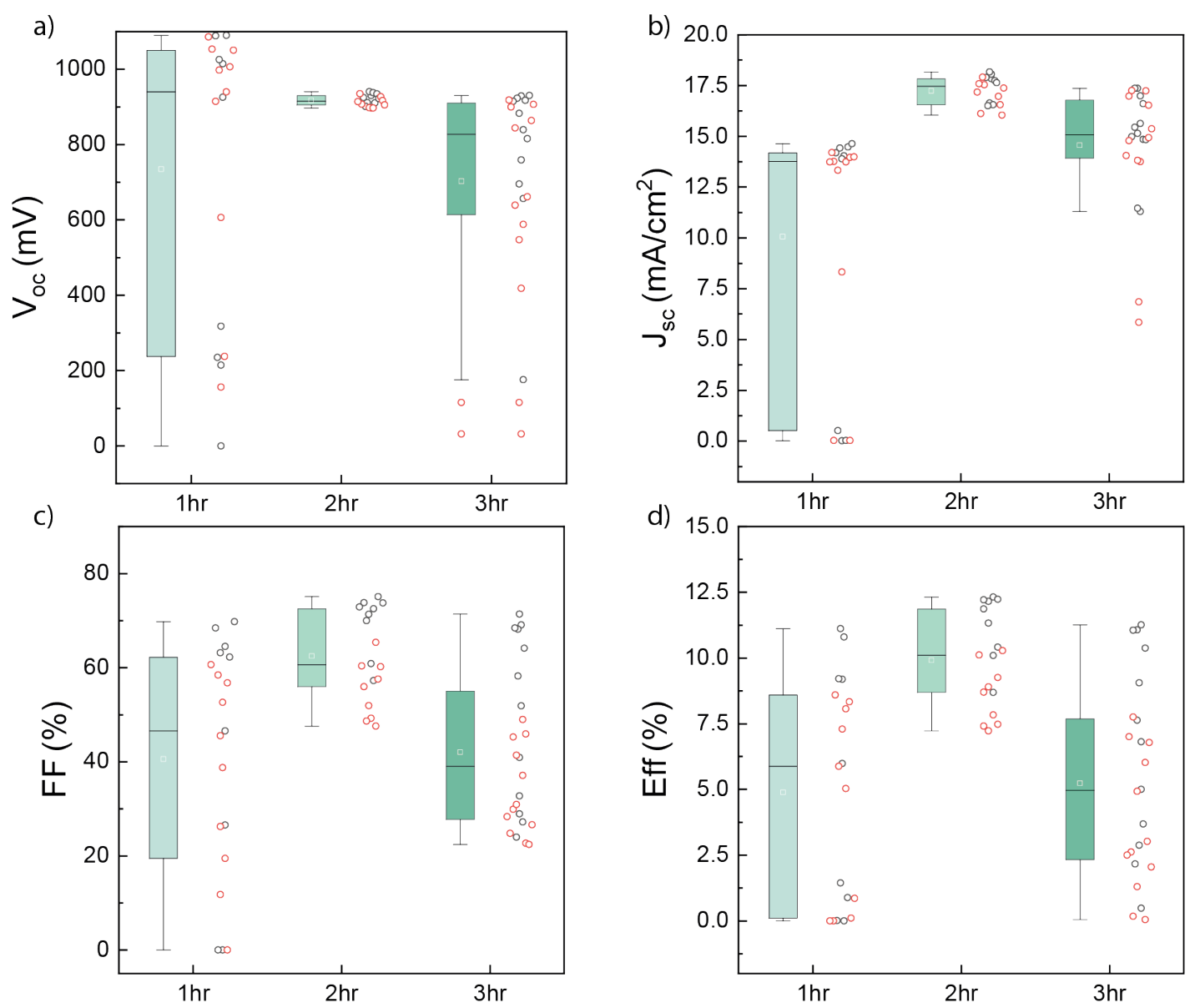

Figure S10: $J-V$ parameters (9-12 cells per condition, reverse and forward scans) for PVD/CVD cell produced with $T_{\text {crucible }}=210{ }^{\circ} \mathrm{C}$ and $T_{\text {substrate }}=140{ }^{\circ} \mathrm{C}$ for an evaporation duration of 1 to 3 hours. a) $V_{\text {oc }}$ b) $J_{\text {sc }}$, c) FF and d) efficiency.

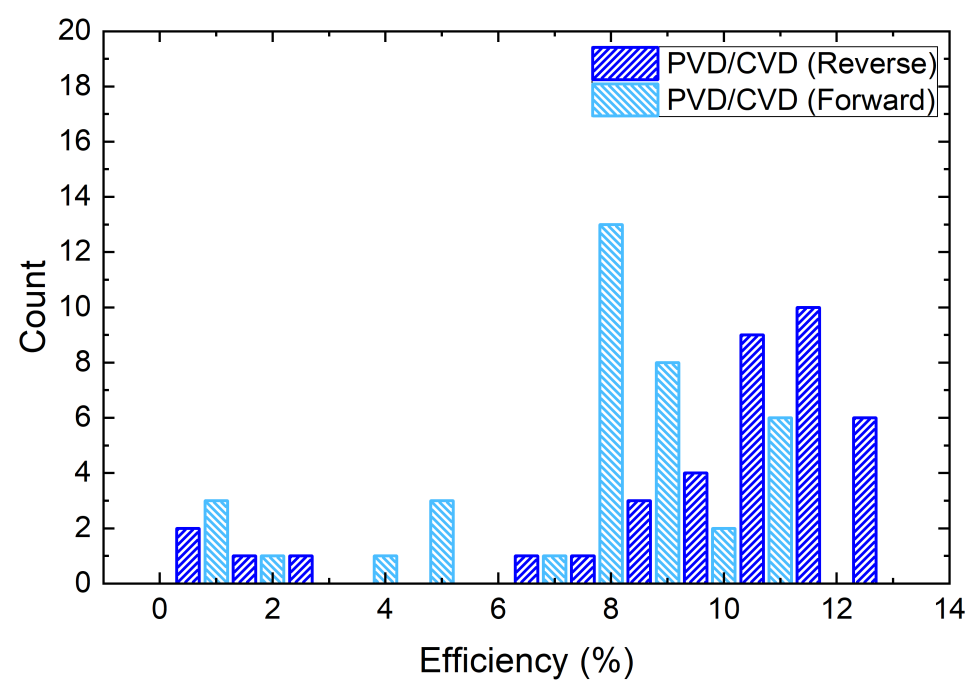


Figure S11: Statistical distribution of reverse and forward scans efficiencies of perovskite solar cells produced by the PVD/CVD method. The deposition conditions are: $T_{\text {crucible }}=210{ }^{\circ} \mathrm{C}$ and $T_{\text {substrate }}=140{ }^{\circ} \mathrm{C}$ for an evaporation duration of 2 hours.

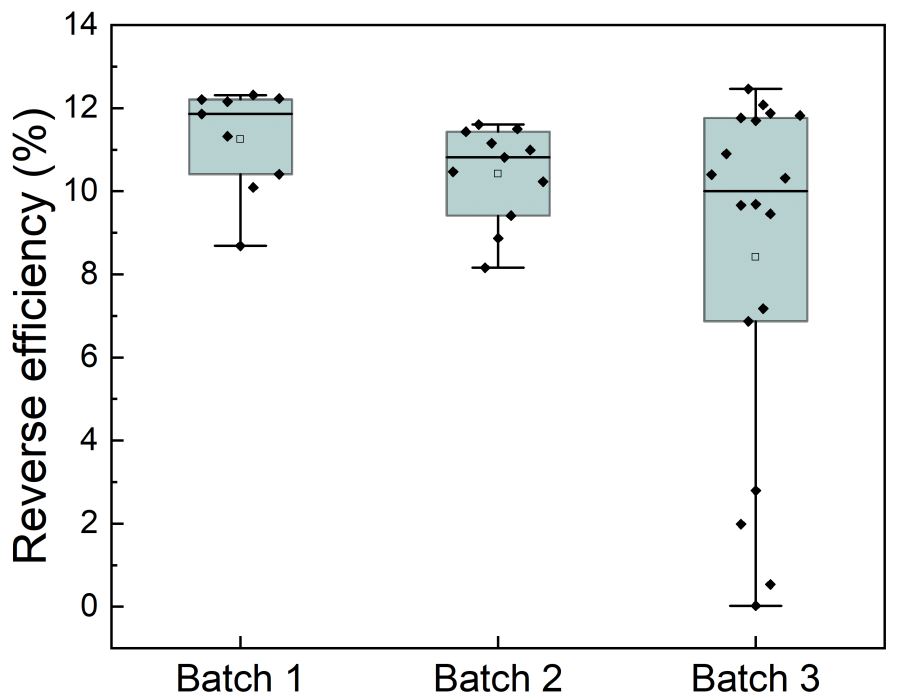

Figure S12: Statistical distribution of reverse scans efficiencies of perovskite solar cells produced by the PVD/CVD method from 3 different batches. The deposition conditions are: $T_{\text {crucible }}=210^{\circ} \mathrm{C}$ and $T_{\text {substrate }}=140{ }^{\circ} \mathrm{C}$ for an evaporation duration of 2 hours.

a) b)

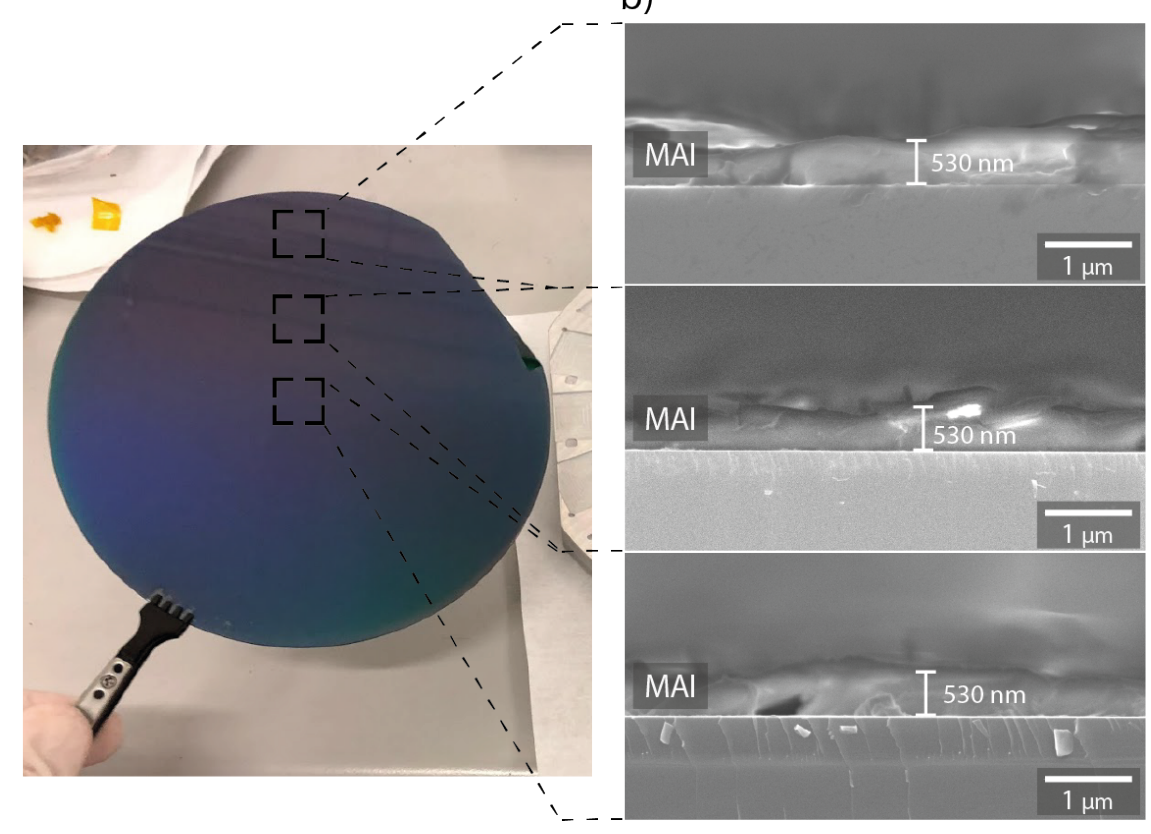


Figure S13: a) Picture of a 6-inch c-Si wafer coated with MAI $\left(T_{\text {substrate }}\right.$ of $\left.70{ }^{\circ} \mathrm{C}\right)$, b) crosssection SEM images taken at the centre (bottom), middle (middle) and edge (top) of the c-Si wafer.

a)

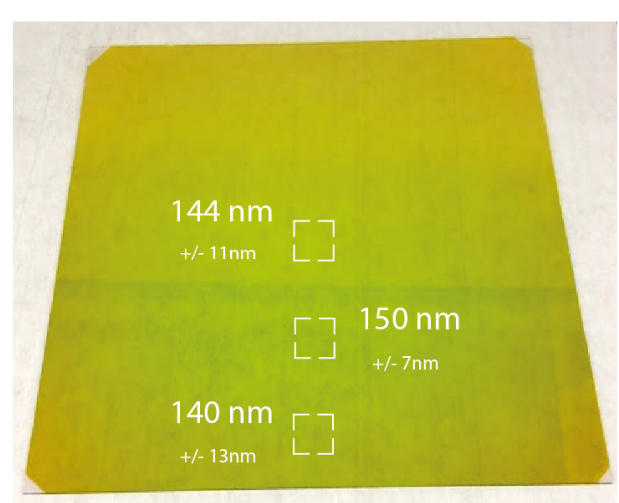

b)

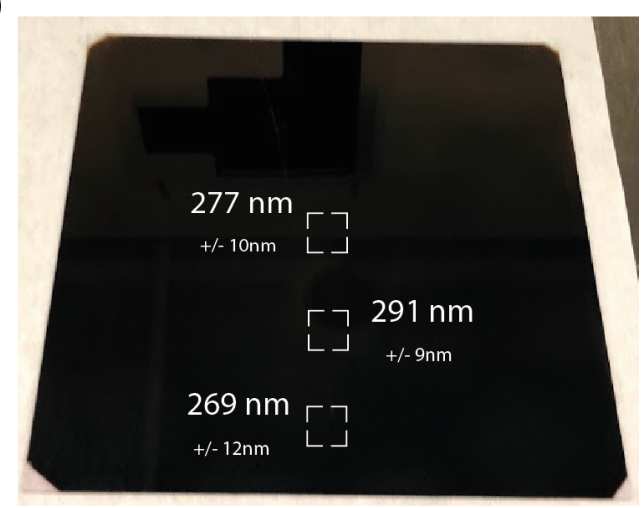

Figure S14: a) $\mathrm{PbI}_{2}$ layer deposited by PVD on a $15 \times 15 \mathrm{~cm}^{2}$ glass/ITO substrate and b) the same template coated with MAI and converted to the perovskite. Thicknesses are measured by profilometry. 